\title{
EFEITO DA DESOSSA E DA MARINAÇÃO SOBRE AS CARACTERÍSTICAS DE PROCESSAMENTO, FÍSICO- QUÍMICAS E SENSORIAIS DO MÚSCULO BICEPS FEMORIS
}

\author{
MARCIA MAYUMI HARADA
}

Dissertação apresentada à Escola Superior de Agricultura "Luiz de Queiroz", Universidade de São Paulo, para obtenção do título de Mestre em Ciências, Área de Concentração: Ciência e Tecnologia de Alimentos.

PIR A CICAB A

Estado de São Paulo - Brasil

Julho - 2004 


\title{
EFEITO DA DESOSSA E DA MARINAÇÃO SOBRE AS CARACTERÍSTICAS DE PROCESSAMENTO, FÍSICO- QUÍMICAS E SENSORIAIS DO MÚSCULO BICEPS FEMORIS
}

\section{MARCIA MAYUMI HARADA}

Médico Veterinário

Orientador: Prof. Dr. JORGE HORII

\author{
Dissertação apresentada à Escola Superior de \\ Agricultura "Luiz de Queiroz", Universidade de São \\ Paulo, para obtenção do título de Mestre em Ciências, \\ Área de Concentração: Ciência e Tecnologia de \\ Alimentos. \\ PI R A C I C A B A \\ Estado de São Paulo - Brasil \\ Julho - 2004
}




\section{Dados Internacionais de Catalogação na Publicação (CIP) DIVISÃO DE BIBLIOTECA E DOCUMENTAÇÃO - ESALQ/USP}

Harada, Márcia Mayumi

Efeito da desossa e da marinação sobre as características de processamento, físico-químicas e sensoriais do músculo Biceps femoris / Márcia Mayumi Harada. - Piracicaba, 2004.

$62 \mathrm{p}$.

Dissertação (mestrado) - - Escola Superior de Agricultura Luiz de Queiroz, 2004.

Bibliografia.

1. Carnes e derivados 2. Corte de alimentos 3. Desossa 4. Músculo (Carne bovina) ! Processamento de alimentos 6 . Salmoura I. Título

CDD 664.92

"Permitida a cópia total ou parcial deste documento, desde que citada a fonte - O autor" 


\section{Dedico e ofereço}

Aos meus pais Tereza e Hatiro pelo amor, educação e ensinamentos Aos meus sobrinhos Bruna e André, irmão Sergio e cunhada Eliane pelo carinho e momentos alegres.

Ao meu noivo Gilberto pela compreensão e apoio de toda hora. 


\section{AGRADECIMENTOS}

À Profa. Dra Carmem J. Contreras Castillo, orientadora da ESALQ/USP, pela amizade e orientação para a realização deste trabalho.

À Dra. Ana Lúcia da Silva Corrêa Lemos, pesquisadora do Centro de Tecnologia de Carnes do ITAL, pela amizade e pela valiosa colaboração na aquisição de conhecimentos neste trabalho.

Ao Centro de Tecnologia de Carnes do Instituto de Tecnologia de Alimentos, através do Dr. Nelson José Beraquet, que autorizou-me a realização deste trabalho cedendo as suas instalações.

À Escola Superior de Agricultura "Luiz de Queiroz"( ESALQ/USP), em especial ao Departamento de Agroindústria, Alimentos e Nutrição pela oportunidade para a realização deste trabalho.

À Fundação de Apoio à Pesquisa do Estado de São Paulo (FAPESP) que financiou a execução deste trabalho.

À Kátia M. Cipolli , Ângela D. Cavenaghi , Hana Arima, Luciana Miyagusku e Susana Cardoso, pelo apoio profissional e amizade de todas as horas.

Ao Juliano Fiori, Vanessa, Elena, Julio, Daniel, Aloise, Roseane e Nelsinho, estagiários do CTC, pela colaboração em cada etapa deste trabalho 
Ao Rivaldo, Orlando, Aparecido, Maristela, Marcia, Marcelo,Nilda, Célia, Fabiana, Tânia, Joseane, Vera, Solenir ,Sandra, Gláucia, Gilca, Ivonete, Rose, amigos e funcionários do CTC pela disposição em ajudar e o espirito de equipe durante o desenvolvimento deste trabalho.

Aos pesquisadores Manuel Pinto Neto, Eunice Yamada, José Ricardo Gonçalves, Renata Bromberg e Expedito Tadeu F. Silveira, do Centro de Tecnologia de Carnes pelos expressíveis conhecimentos técnicos.

À Vanessa, Cris, Nilo, Camila, Karina e Christtian, colegas da pósgraduação, por compartilhar os bons momentos da vida.

À Rhodia pelo fornecimento do tripolifosfato de sódio

A todas as pessoas que de alguma maneira, tornaram possível a realização deste trabalho.

E a Deus.

Minha gratidão 


\section{SUMÁRIO}

Página

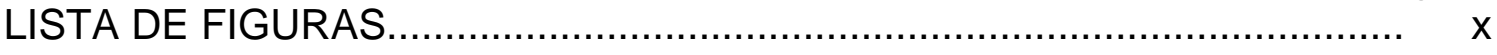

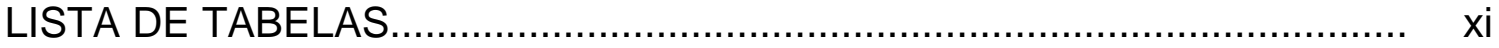

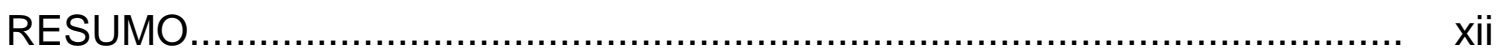

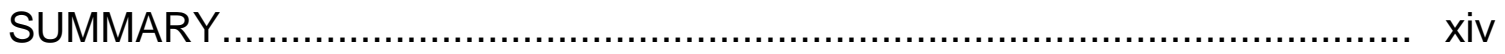

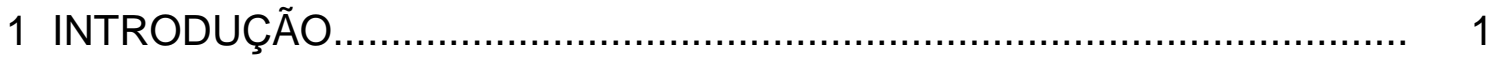

2 REVISÃO DE LITERATURA.................................................................. 3

2.1 Estimulação elétrica..................................................................... 3

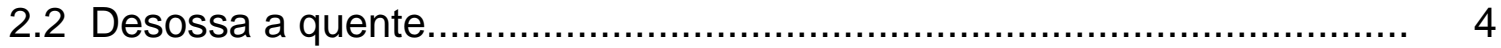

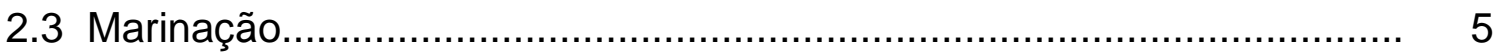

2.4 Tratamento com cloreto de cálcio.................................................... 7

2.5 Ação dos polifosfatos................................................................. 8

2.6 Considerações sobre a maciez da carne bovina................................... 9

2.6.1 Métodos de avaliação de textura.................................................... 10

3 MATERIAL E MÉTODOS...................................................................... 12

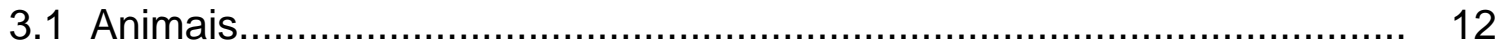

3.2 Embarque e transporte dos animais da propriedade ao abatedouro....... 12

3.3 Delineamento experimental........................................................ 12

3.4 Delineamento estatístico............................................................. 13

3.5 Condições experimentais............................................................ 15

3.5.1 Local de abate..................................................................... 15

3.5.2 Insensibilização dos animais....................................................... 15 
3.5.3 Estimulação elétrica das carcaças................................................... 15

3.5.4 Condicionamento e resfriamento dos cortes..................................... 15

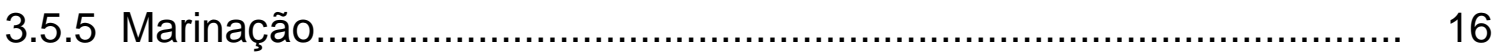

3.5.6 Porcionamento dos músculos, embalagem, congelamento e

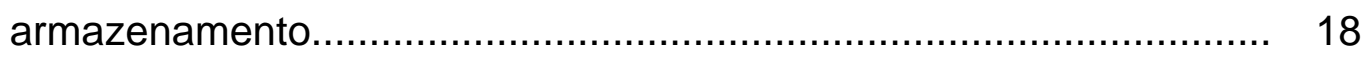

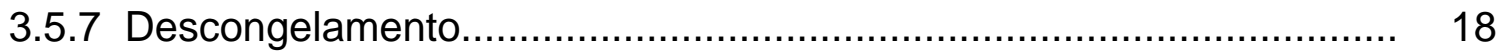

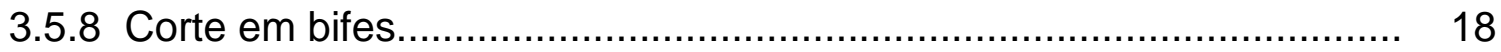

3.5.9 Cozimento e preparo geral das amostras....................................... 18

3.6 Respostas experimentais......................................................... 19

3.6.1 Caracterização da matéria-prima.................................................. 19

3.6.2 Perdas de peso no descongelamento.............................................. 19

3.6.3 Perdas de peso no cozimento..................................................... 19

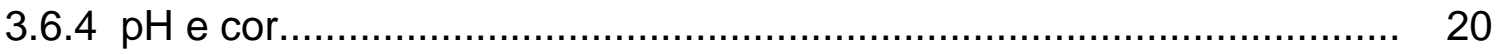

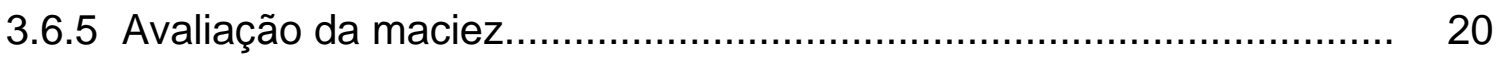

3.6.5.1 Determinação da força de cisalhamento....................................... 20

3.6.5.2 Análise sensorial................................................................. 21

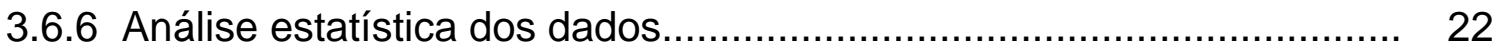

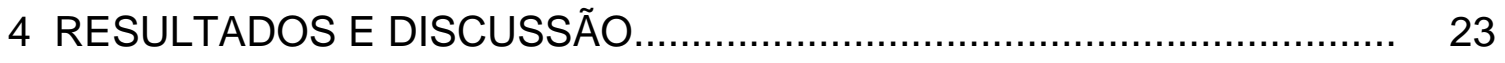

4.1 Avaliação química.......................................................................... 23

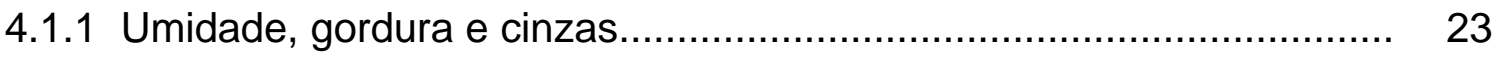

4.1.2 Proteína e colágeno.................................................................. 26

4.2 Avaliação de processamento ........................................................ 27

4.2.1 Força de cisalhamento e nível de injeção......................................... 27

4.2.2 Perda de peso no descongelamento (PPD) e perda de peso na

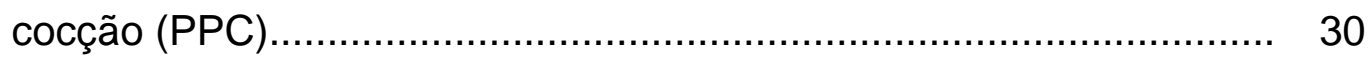

4.3 Avaliação sensorial.................................................................. 33

4.3.1 Maciez e suculência....................................................................... 33

4.3.2 Sabor salgado, metálico, amargo e de sabão................................... 36

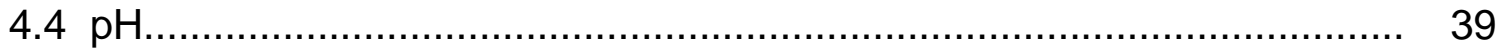




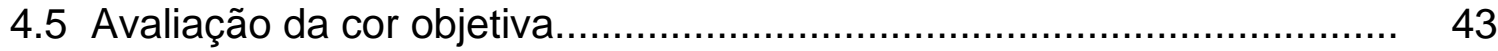

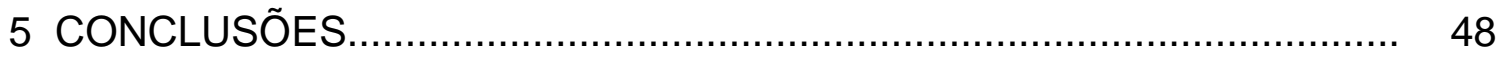

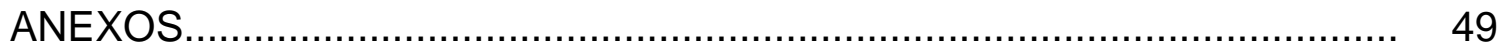

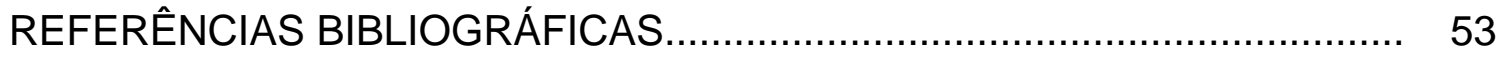




\section{LISTA DE FIGURAS}

Página

1 Delineamento experimental da avaliação do tipo de desossa e tipo de marinação do corte Biceps femoris................................................... 14

2 Porcionamento do corte Bíceps femoris para as análises................... 17

3 Ficha de avaliação sensorial de provador treinado.............................. 22

4 Interação do efeito desossa x salmoura e sua influência na suculência no músculo Biceps femoris......................................................... 36

5 Interação do efeito desossa $\times$ salmoura e sua influência na avaliação de sabor salgado no músculo Biceps femoris................................... 39

6 Interação do efeito desossa x salmoura e sua influência na avaliação de $\mathrm{pH}$ após descongelamento no músculo Biceps femoris................... 42

7 Interação do efeito desossa x salmoura e sua influência no pH após descongelamento no músculo Biceps femoris.................................. 42

8 Interação do efeito desossa x salmoura e sua influência na avaliação de $b^{\star}$ apósmarinação no músculo Biceps femoris................................ 47

9 Interação do efeito desossa $x$ salmoura e sua influência na avaliação de $b^{\star}$ após descongelamento no músculo Biceps femoris. 


\section{LISTA DE TABELAS}

Página

1 Composição das salmouras utilizadas no processo de marinação do músculo Bíceps femoris.

2 Efeito da desossa e do tipo de salmoura nas avaliações de umidade, gordura e cinzas do músculo Biceps femoris.

3 Efeito da desossa e do tipo de salmoura nos teores de proteína e colágeno do músculo Biceps femoris.

4 Efeito da desossa e do tipo de salmoura nas características da força de cisalhamento e nível de injeção do músculo Biceps femoris.

5 Efeito da desossa e do tipo de salmoura na perda de peso no descongelamento (PPD) e na perda de peso na cocção do músculo Biceps femoris.

6 Efeito da desossa e do tipo de salmoura na avaliação sensorial do músculo Biceps femoris.....

7 Efeito da desossa e do tipo de salmoura no sabor do músculo Biceps femoris.

8 Efeito da da desossa e o tipo de salmoura no pH do músculo Biceps femoris.

9 Efeito da desossa e do tipo de salmoura nas cor objetiva $L^{*} a^{\star}$ e $b^{*}$ antes e após a marinação do músculo Biceps femoris. 
10 Efeito da desossa e do tipo de salmoura na cor objetiva $L^{*} a^{\star}$ e $b^{\star} a$ após o processo de descongelamento do músculo Biceps

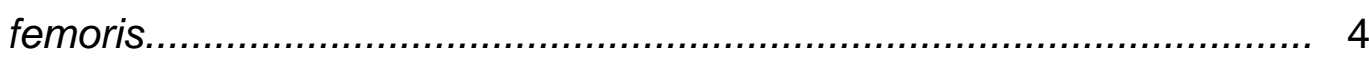

11 Valores de $\mathrm{F}$ e respectivos níveis de significância $(P)$ associados ao teste ANOVA dos efeitos de desossa e salmoura sobre as variáveis químicas e de processamento do músculo Biceps femoris

12 Valores de $\mathrm{F}$ e respectivos níveis de significância $(P)$ associados ao teste ANOVA dos efeitos de desossa e salmoura sobre as variáveis de $\mathrm{pH}$ e cor do músculo Biceps femoris.

13 Valores de $\mathrm{F}$ e respectivos níveis de significância $(P)$ associados ao teste ANOVA dos efeitos de desossa e salmoura sobre os parâmetros de avaliação sensorial do músculo Biceps femoris. 


\title{
INFLUÊNCIA DA DESOSSA E DA MARINAÇÃO SOBRE AS CARACTERÍSTICAS DE PROCESSAMENTO, FÍSICO-QUÍMICAS E SENSORIAIS DO MÚSCULO BICEPS FEMORIS (COXÃO DURO)
}

\author{
Autora: MARCIA MAYUMI HARADA \\ Orientador: Prof. Dr. JORGE HORII
}

\section{RESUMO}

O processo acelerado de obtenção da carne oferece grande vantagem à indústria, podendo encurtar alguns estágios de produção através da combinação de técnicas como a estimulação elétrica de carcaças, a desossa a quente e a marinação. O presente estudo foi realizado com o objetivo de avaliar a forma de desossa e o tipo de marinação em corte do músculo traseiro de bovinos (coxão duro) da raça Nelore. Determinou-se o efeito da desossa a quente e a frio e o efeito da salmoura de marinação, uma contendo 1,6\% ( $250 \mathrm{mM}$ ) de cloreto de cálcio e $2,4 \%$ de cloreto de sódio e outra com 1,8\% de tripolifosfato de sódio e $2,4 \%$ de cloreto de sódio. Foram realizadas análises que incluíram a composição centesimal, teor de colágeno, pH, cor objetiva, textura objetiva (força de cisalhamento), perda de peso no cozimento e avaliação de maciez, suculência e sabor em cada músculo analisado. A marinação reduziu a força de cisalhamento, assim como aumentou a maciez e a suculência avaliadas pela equipe sensorial. Por outro lado a força de cisalhamento foi reduzida com a desossa quente e a maciez e a suculência aumentadas pela desossa frio. A cor foi o atributo mais afetado negativamente 
pelo processo de marinação, o valor $a^{*} e b^{\star}$ apresentou redução indicando escurecimento do vermelho, especialmente com a salmoura contendo cloreto de cálcio. A desossa interferiu no valor de $a^{*} e b^{\star}$ após o descongelamento indicando uma diminuição de $a^{*}$ e de $b^{\star}$ na desossa quente. A desossa a quente poderá ser aplicada com sucesso em cortes bovinos provenientes de carcaças estimuladas eletricamente a baixa voltagem, sem provocar alterações negativas nos cortes. A marinação com salmoura contendo cloreto de sódio e tripolifosfato podem melhorar sensivelmente a maioria dos atributos avaliados, mas provoca alterações marcantes na cor. 


\title{
EFFECTS OF BRINE COMPOSITION AND DEBONING ON PROCESSING, PHYSICAL-CHEMICAL AND SENSORY CHARACTERISTICS OF BICEPS FEMORIS MUSCLE (OUTSIDE ROUND)
}

\author{
Author: MARCIA MAYUMI HARADA
}

Adviser: Prof. Dr. JORGE HORII

\section{SUMMARY}

The accelerated process to obtain meat offer advantages to the meat industry, and can reduce some of the stages of production through electrical stimulation of carcass, hot boning and enhancement process. In this work muscles from top round (Bíceps femoris) from Nelore steers were deboned using conventional and hot processing and marinated. The effect of deboning process and two brine solutions containing 1,6\% calcium chloride and 2,4\% sodium chloride and 1,8\% sodium tripolyphosphate and $2,4 \%$ sodium chloride were evaluated. Proximate percent composition, collagen, $\mathrm{pH}$, colour, texture (Warner Bratzler shear force), cooking loss, tenderness, juiciness and flavor in each muscle were analysed. Enhacement process reduced shear force value, increased tenderness and juiciness from sensory panel. Otherwise the shear force was reduced with hot deboned and tenderness and juiciness reduced by conventional deboning. Colour analysis was affected by enhancement process, $a^{*}$ and $b^{*}$ value showed decreased indicating darkness red colour, specially with calcium chloride brine. Hot deboning can be succesfully used in beef meat in addition to low electrical stimulaton carcass without negative alteration in meat. 
Enhancement process with calcium chloride, sodium tripolyphosphate and sodium chloride can improve the major of analysed attributes, but provoke colour modifications. 


\section{INTRODUÇÃO}

O Brasil possui um rebanho bovino de 168 milhões de cabeça e deverá crescer aproximadamente $8,5 \%$ nos próximos 10 anos. É considerado o quinto maior consumidor per capita mundial de carnes, com 36,2 kg/pessoa/ano e uma produção estimada de 7,7 milhões de toneladas/carcaça/ano (Anualpec, 2003).

A maciez é o fator mais importante de palatabilidade na aceitação de carnes cozidas. Muitos fatores têm sido relacionados às alterações de maciez da carne, dentre eles destacam-se idade, raça, sexo, pouca gordura, manejo de pré-abate, resfriamento das carcaças e métodos de cozimento (Oreskovich et al., 1992).

Com o intuito de acelerar o estabelecimento do rigor mortis, reduzindo-se o período de espera para a desossa, faz-se uso da estimulação elétrica, dinamizando os processos de obtenção dos cortes, embalagem e resfriamento.

Outras técnicas de amaciamento podem ser combinadas à estimulação, tais como a maturação e a marinação. O processo de marinação, que permite alterar a textura da carne de modo rápido, pode ser aplicado de duas maneiras: estaticamente (imersão) ou dinamicamente (injeção e massageamento) (Rocha, 2000).

A carne proveniente de carcaças desossadas a quente apresenta $\mathrm{pH}$ final elevado o que aumenta sua capacidade de retenção de água e maciez. O uso de inibidores de glicólise, tais como o $\mathrm{CaCl}_{2}$ e o próprio $\mathrm{NaCl}$, através do aumento da força iônica, têm se demonstrado eficazes na melhoria da maciez 
das carnes. Os resultados são controversos no que se refere a alguns atributos sensoriais (sabor e cor), que alguns autores consideram prejudicados quando se adiciona $\mathrm{CaCl}_{2}$ (Morgan et al.,1991).

Os polifosfatos vêm sendo bastante utilizados na produção de cortes marinados provenientes de diferentes carnes. Sabe-se que os polifosfatos melhoram o rendimento, a maciez e a retenção de água pela carne. $\mathrm{O}$ mecanismo de ação dos polifosfatos na carne não é completamente conhecido, porém sabe-se que elevam o $\mathrm{pH}$, aumentam a força iônica, seqüestram íons metálicos, dissociam o complexo actomiosínico, o que se reflete no aumento da maciez e da suculência da carne. Os polifosfatos apresentam efeito sinergístico com o NaCl (Sheard et al., 1999).

A possibilidade de se agregar valor a cortes menos valorizados e facilitar seu preparo vem ao encontro das necessidades e oportunidades do mercado para novos serviços do varejo, através da comercialização de produtos cárneos de preço acessível, com preparo rápido e maciez. Conseqüentemente é essencial desenvolver diferentes processos post-mortem adaptados à realidade nacional, com objetivo de maximizar a maciez da carne. Esses processos devem considerar principalmente os músculos que são tradicionalmente mais duros e, portanto, menos aceitos pelo mercado, onde são comercializados a preços menores. 


\section{REVISÃO DE LITERATURA}

\subsection{Estimulação elétrica}

O estímulo elétrico da musculatura das carcaças de animais de abate tem despertado considerável interesse nos últimos anos, como forma de acelerar a queda de $\mathrm{pH}$ e o estabelecimento do rigor mortis. Esta prática, já adotada comercialmente em vários países, ainda é pouco utilizada nos

frigoríficos brasileiros. É uma técnica particularmente útil quando se pretende refrigerar ou congelar rapidamente carcaças, meias carcaças, quartos ou cortes logo depois do sacrifico, pois ao acelerar a queda de $\mathrm{pH}$ até alcançar seu valor final, elimina-se o risco de encurtamento pelo frio e subseqüente endurecimento da carne. Também pode ser acelerado o amaciamento ou maturação natural e o avermelhamento da carne com a estimulação elétrica (Bendall, 1984).

Embora muitos estudos relatem o efeito positivo da estimulação elétrica na maciez da carne, a intensa estimulação combinada com o resfriamento lento pode acarretar efeitos adversos na maciez da carne. Além disso, alguns estudos relatam um efeito negativo sobre a capacidade de retenção de água e a estabilidade da cor (Geesink et al., 2001).

O amaciamento da carne devido à estimulação elétrica tem sido atribuído principalmente a três fatores: a prevenção do encolhimento pelo frio (ao promover uma aceleração na glicólise e na resolução do rigor mortis antes da temperatura do músculo baixar a valores críticos); a aceleração da atividade proteolítica (mediada pela ação do cálcio) e às rupturas físicas causadas na 
estrutura da fibra muscular (devidas às extremas contrações musculares) (Hedrick, 1994).

A estimulação elétrica melhora a maciez e também ajuda na etapa da sangria e na retirada do couro. Em todos os estudos no qual a estimulação elétrica foi utilizada corretamente, houve uma melhora na maciez e conforme Taylor, (2003) persiste como a melhor tecnologia para assegurar a qualidade da carne.

\subsection{Desossa a quente}

A desossa a quente ou desossa da carcaça com o músculo em prérigor, corresponde à retirada dos músculos da estrutura óssea antes que a temperatura corporal do animal seja substancialmente reduzida, o que significa diminuição do tempo normal entre o abate e a desossa. Esta técnica, utilizada há muitos anos, especialmente em países em desenvolvimento, despertou interesse em vários países, onde vem sendo objeto de inúmeras pesquisas, pois pode aumentar a produtividade dos abatedouros, além de reduzir o consumo de energia no resfriamento.

A desossa a quente (DQ) busca alcançar melhor controle na taxa de resfriamento da carne, uma vez que é ela que permite a redução da carcaça à pequenas peças, onde a troca de temperatura se dá mais rapidamente. $A D Q$ imediatamente após a esfola e evisceração, e antes de qualquer resfriamento, é o meio mais efetivo de se minimizar as perdas por evaporação e o tempo de resfriamento da carne (Pisula \& Tyburcy, 1996). Entretanto, é importante que a qualidade final da carne não seja alterada em virtude do endurecimento causado pelos fenômenos de encolhimento (Corte, 1981). Se os músculos excisados forem resfriados ou congelados antes da resolução do rigor mortis, podem endurecer sensivelmente em função tanto do encurtamento pelo frio (cold shortening) com temperaturas abaixo de $10-15^{\circ} \mathrm{C}$, como pelo calor, pela 
rigidez de descongelação (thaw rigor) e perda por gotejamento na faixa de 8 a $12^{\circ} \mathrm{C}$ (Honikel et al.,1987). O encurtamento das miofibrilas na fase pós abate pode ser responsável por extremas variações da maciez, muitas vezes anulando uma série de práticas anteriores destinadas a produzir uma carne de melhor qualidade.

Os músculos retirados da carcaça através do processo de desossa a quente podem se contrair livremente, por estarem separados dos ossos, daí a importância de se utilizar a DQ em conjunto com outras técnicas que: i) acelerem o rigor mortis, como a estimulação elétrica, ou, ii) que propiciem a resolução do rigor mortis ou a queda do $\mathrm{pH}$, acelerando o processo de maturação. Uma dessas técnicas é o controle do resfriamento inicial à temperatura ambiente ou a temperaturas superiores a $10^{\circ} \mathrm{C}$.

O período post mortem, a temperatura e a taxa de glicólise podem afetar as características da qualidade da carne, especialmente os cortes provenientes da desossa a quente. Durante a desossa a quente a carne está no período pré rigor e o valor do pH pode ser elevado (Boles \& Swan, 1997).

\subsection{Marinação}

A marinação é um processo que vem sendo utilizado há muitos anos, tendo em vista a observação de que a imersão da carne em salmoura adicionado de simples ingredientes melhorava o sabor da mesma, além de mascarar alguns odores indesejáveis. Inicialmente o processo era usado como prática culinária, mas com o desenvolvimento da indústria frigorífica, a prática da marinação foi amplamente adotada por esta indústria para a produção em larga escala (Gault, 1985 ).

A qualidade da carne é importante tanto para a indústria como para os consumidores. Sob a perspectiva dos consumidores é importante avaliar-se a intenção de compra e a palatabilidade. Em relação à intenção de compra, a 
aparência é muito importante, especialmente a cor e em relação à palatabilidade, os atributos de interesse são maciez, suculência e sabor, os quais determinam a repetição da compra (Brewer et al., 1999).

A indústria vem buscando tecnologias que melhorem os fatores associados com a intenção de compra e a palatabilidade. Uma destas tecnologias é denominada "enhancement" (melhoramento), que consiste em se injetar uma solução na carne fresca para aumentar a retenção de fluidos pela carne e incrementar os atributos de palatabilidade. Esta tecnologia, trata-se na verdade de marinação, porém não são agregados condimentos ou flavorizantes, restringindo-se ao cloreto de sódio, em baixas concentrações e aos polifosfatos (Brashear et al., 2002).

Os métodos de marinação são compostos pela imersão, injeção e massageamento. A imersão é o método mais antigo, consiste em submergir a carne na salmoura e permite que os ingredientes penetrem na carne através da difusão de acordo com o tempo (Xargayó, 2001).

Na marinação por injeção, a salmoura é injetada por meio de agulhas, sob pressão, para o interior do músculo. Basicamente, a absorção da salmoura é determinada pela pressão de injeção e pela velocidade da esteira, que desloca o corte. As vantagens deste método são: uniformidade do produto marinado; facilidade de aplicação em grandes volumes de produção; redução de mão de obra; devido à perfuração, rapidez de cozimento; melhoria da maciez e da suculência da carne. As desvantagens são: elevado custo inicial com equipamentos, não pode ser utilizado para produtos cominuídos e formados; não é recomendado para injeção de salmouras com ingredientes cujas partículas obstruam as agulhas; em alguns produtos, a exsudação (drip) é maior se comparada à observada nos processos de marinação por outros sistemas; o processo pode carregar patógenos da superfície para o interior da carne (Lemos et al., 1999). 


\subsection{Tratamento com cloreto de cálcio}

A elevação na concentração de cálcio no músculo post mortem é a principal causa do amaciamento que se desenvolve na carne durante o processo de maturação, uma vez que este íon é um agente indispensável à ação das calpaínas (Delgado, 2001).

O íon cálcio ativa as calpaínas (proteínases endógenas): $\mu$-calpaína, m-calpaínas e calpastatina, esta última inibidora das outras duas, que são responsáveis pela quebra das proteínas miofibrilares (Koohmaraie, 1988). A concentração de cálcio endógeno imediatamente pós-abate é suficiente para ativar a $\mu$-calpaína, porém não a m-calpaína. Assim, quando a concentração de cálcio aumenta, liberado do retículo endoplasmático e mitocôndria, a mcalpaína é ativada, o que provoca maior tenderização (Dransfield, 1994). Um mecanismo análogo poderia ser utilizado para explicar o amaciamento post mostem observado quando o cloreto de cálcio é aplicado no intervalo de até 36 horas pós abate. Neste caso a carne é tratada com concentrações de cálcio maiores que as presentes naturalmente no músculo, com objetivo de acelerar a tenderização (Dransfield, 1994). Por outro lado, este tratamento pode provocar alterações em algumas propriedades sensoriais da carne, tais como cor e sabor, dependendo da concentração de cálcio adicionada (Landsell et al., 1995).

Inúmeros estudos indicam que a maciez da carne foi aumentada drasticamente através da infusão de $\mathrm{CaCl}_{2}$ nas carcaças (Koohmaraie, 1988, Koohmaraie \& Shackelford, 1991) ou via injeção de porções da carcaça bovina (Koohmaraie et al., 1990). Estes autores ainda observaram que o aumento do teor de cálcio via adição da solução não provocava endurecimento resultante da contração dos músculos remanescentes na carcaça até resolução completa do rigor mortis.

O tratamento de carnes com cloreto de cálcio tem se tornado um método popular no amaciamento da carne. O cloreto de cálcio já é aprovado 
pelo USDA para uso em concentrações de até $3 \%$ de uma solução $0,8 \mathrm{M}$ para amaciamento de carnes.

Gonzalez et al.( 2001) realizaram um estudo com o músculo Cutaneus truncci onde o objetivo foi determinar o efeito do tratamento $\operatorname{com~} \mathrm{CaCl}_{2}$ na maciez do músculo, permitindo reduzir o período de maturação necessário para melhoria da maciez.

\subsection{Ação dos polifosfatos}

Os polifosfatos constituem-se no composto mais comumente utilizado em salmouras para marinação, eleva o pH da carne, o que reflete no aumento da capacidade de retenção de água, na redução à purga, na melhora do sabor, na estabilidade da cor (Keeton, 1983) e na suculência (Sheard et al., 1999).

Os fosfatos são sais do ácido fosfórico e incluem tanto os ortofosfatos com um único átomo de fósforo como os polifosfatos com dois ou mais átomos de fósforo na molécula. Os polifosfatos são compostos químicos que atuam como agentes tamponantes e sequestrantes, bem como polianions que aumentam a força iônica (Steinhauer, 1983; Halliday, 1978).

Em produtos cárneos não curados os primeiros estudos indicavam que a injeção de cortes cárneos com tripolifosfato, isoladamente ou misturas com metafosfato, acrescido de sal, melhorava várias propriedades, destacando-se a diminuição da exsudação durante a estocagem refrigerada, considerada muito interessante, pois naquela época iniciava-se o conceito de desossa centralizada e transporte dos cortes para comercialização em supermercados, onde permaneciam armazenados. Urbain et al.,(1968) relataram que a imersão de cortes cárneos por 30 segundos em solução contendo polifosfatos, seguido de estocagem durante três semanas, reduziu significativamente a exsudação. Em cortes injetados cozidos, foi observado que estes apresentaram redução da

perda de peso no cozimento, o que se refletiu no aumento da suculência e da 
maciez; além de retardar a oxidação durante a estocagem e permitir o cozimento durante um tempo mais longo, com melhoria do aroma de carne grelhada e manutenção da suculência.

Um processo amplamente discutido, mas não muito conhecido, é a interação entre $\mathrm{NaCl}$ e tripolifosfato de sódio (Lawrie, 1985; Young et al.,1992). O entendimento desta interação poderia melhorar a eficácia dos métodos de marinação utilizados pela indústria frigorífica.

Os trabalhos recentes com carne bovina buscam estudar o efeito da adição de soluções contendo tripolifosfato de sódio e cloreto de sódio em cortes bovinos, com objetivo de melhorar a maciez dos mesmos cozidos e avaliar o efeito da adição em parâmetros de rendimento (Boles \& Shand, 2001).

\subsection{Considerações sobre a maciez da carne bovina}

A maciez é a característica mais importante de palatabilidade da carne, sendo um indicador de textura do alimento e podendo ser definida de várias formas, tais como, a facilidade com que a carne se deixa mastigar, a facilidade de penetração e corte, ou, ainda a resistência de ruptura das miofibrilas ao longo da mastigação. A preferência dos consumidores pela carne macia é unânime, embora os aspectos de qualidade visual da carne crua, tais como a coloração do músculo e da gordura, a proporção músculo: gordura, a marmorização, a firmeza do tecido muscular e a textura visual (grão da carne) também sejam determinantes na hora da compra (Felício, 1995; Miller, 1997).

A maciez da carne é decorrência de um conjunto de fatores. Sabe-se, hoje, que fatores relacionados ao animal, tais como raça, sexo, manejo, alimentação e, principalmente, maturidade, seguidos de vários tratamentos aplicados à carcaça ou aos cortes cárneos no período que sucede o abate, influenciam a maciez e, muitos deles, podem ser controlados para produzir uma carne de melhor qualidade gustativa. Sabe-se também que todos estes fatores, 
anteriores ou posteriores ao abate, exercem ação sobre as proteínas do tecido conjuntivo e/ou dos componentes fibrilares do músculo (Kastner \& Felício, 1980).

A textura é definida por (Szczesniak, 1963) como a manifestação sensorial e funcional das propriedades estruturais e mecânicas dos alimentos, detectadas através do senso de visão, audição, toque e cinestética. As propriedades mecânicas foram relacionadas à resistência dos alimentos à aplicação de uma força (dureza, coesividade, viscosidade, elasticidade e adesividade); as geométricas, relacionadas ao tamanho, formato e orientação das partículas no alimento (fibroso, cristalino, granuloso, etc); e outras, características relacionadas com a percepção da umidade, teor de óleos e gorduras do alimento (oleosidade, suculência, etc.).

\subsubsection{Métodos de avaliação de textura}

A textura, notadamente a maciez inerente a diferentes cortes da carne bovina determinam o preço que o consumidor está preparado ou espera pagar por cada um deles. Sendo o item mais caro no orçamento alimentar, a carne, dentre todos os produtos alimentícios em que a textura é um importante fator na aceitação do consumidor, vem recebendo grande atenção pelos cientistas do mundo.

Os termos textura e maciez são usados alternadamente como atributo de qualidade sensorial da carne, entretanto, enquanto textura é uma propriedade sensorial de um alimento, a qual inclui todas as sensações quinestéticas percebidas na boca, maciez é apenas um atributo de textura, podendo ser definida como a resistência da carne ao corte. O termo dureza pode também ser utilizado para definir esta característica sensorial (Szczesniak, 2002). 
Entretanto, apesar de ser uma característica sensorial, a maciez pode também ser avaliada através de métodos mecânicos instrumentais. A vantagem da medição por instrumentos é que estes fornecem medidas objetivas que podem ser facilmente repetidas um grande número de vezes em um determinado período de tempo, geralmente menor que aqueles requeridos pelas avaliações sensoriais. 


\section{MATERIAL E MÉTODOS}

\subsection{Animais}

Foram utilizados no presente estudo 36 cortes de coxão duro provenientes de 36 bovinos da raça Nelore (Bos indicus), machos castrados. Os animais foram abatidos em torno de 30 a 36 meses de idade, peso vivo médio de 435,3kg e originários de propriedade particular do Estado de São Paulo e mantidos no Instituto de Zootecnia, em Nova Odessa (à $30 \mathrm{Km}$ de Campinas) antes da dieta hídrica e do abate .

\subsection{Embarque e transporte dos animais da propriedade ao abatedouro}

A forma de embarque e de transporte dos animais na propriedade foi realizada visando o menor estresse possível dos mesmos.

\subsection{Delineamento eperimental}

O presente estudo contou com 6 tratamentos conduzidos com o corte Biceps femoris denominado coxão duro.

Um processo de abate, duas forma de desossa tipos de desossa (quente e fria) e de marinação com dois tipos de salmoura tripolifosfato de sódio 
e cloreto de sódio(TPP/NaCl) e cloreto de cálcio e cloreto de sódio $\left(\mathrm{CaCl}_{2} /\right.$ $\mathrm{NaCl}$ ) e o controle foram testados.

As unidades experimentais são os músculo de traseiro Biceps femoris (Coxão Duro) de uma meia carcaça, que foram submetidos aos tratamentos Desossa a frio não marinado (DFNM), Desossa fria marinado com $\mathrm{CaCl}_{2} / \mathrm{NaCl}$ (DFMC), Desossa fria marinado com TPP/NaCl (DFMT), Desossa quente não marinado (DQNM), Desossa quente marinado com $\mathrm{CaCl}_{2} / \mathrm{NaCl}(\mathrm{DQMC})$ e Desossa quente marinado com TPP/NaCl (DQMT), conforme Figura 1.

Para a obtenção da comparação entre as médias dos tratamentos e de uma estimativa do erro experimental, cada tratamento sofreu 2 repetições e 3 replicações.

\subsection{Delineamento estatístico}

Para a distribuição dos tratamentos nas unidades experimentais foi utilizado um delineamento em blocos estendidos ao acaso, considerando como fator de blocagem o dia de abate (12 animais por dia / 2 para cada tratamento).

A atribuição dos tratamentos dentro dos blocos foi feita de maneira aleatória, proporcionando uma uniformidade de condições dos diferentes fatores do meio ambiente no dia do abate, evitando que estes afetem o efeito dos tratamentos.

Avaliou-se o efeito dos seis tratamentos e, através de um experimento fatorial $2 \times 3$, avaliou-se os fatores forma de desossa ( quente e fria) e tipo de salmoura de marinação (polifosfatos de sódio/cloreto de sódio - TPP/NaCl e cloreto de cálcio/cloreto de sódio $-\mathrm{CaCl}_{2} / \mathrm{NaCl}$ ), além das possíveis interações. 


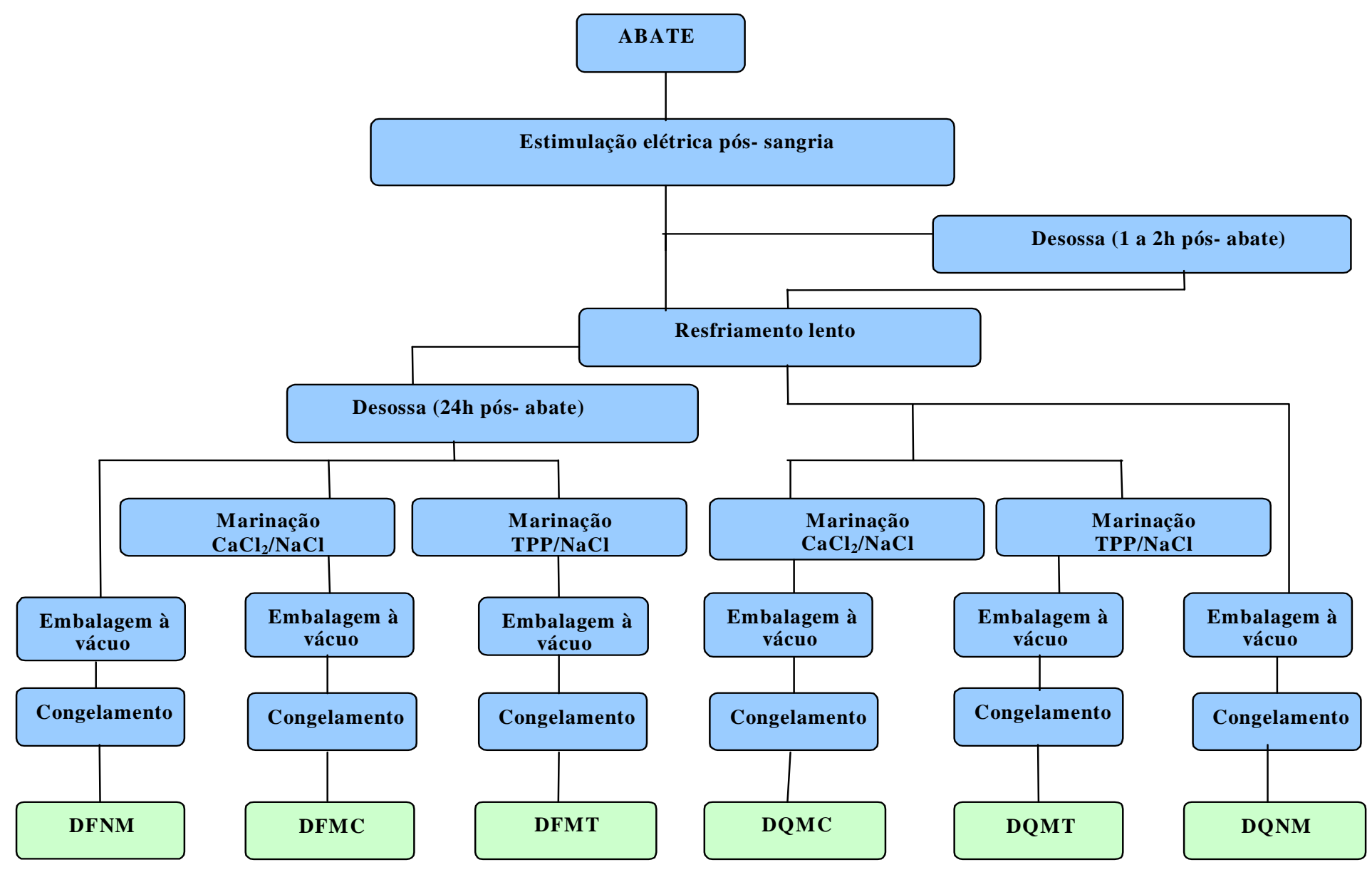

Figura 1 - Delineamento experimental da avaliação do tipo de desossa e tipo de marinação do corte Biceps femoris

DFNM = Desossa fria não marinado DQNM = Desossa quente não marinado
DFMC = Desossa fria marinado com $\mathrm{CaCl}_{2} / \mathrm{NaCl} \quad$ DFMT $=$ Desossa fria marinado com TPP $/ \mathrm{NaCl}$ DFMC $=$ Desossa quente marinado com $\mathrm{CaCl}_{2} / \mathrm{NaCl}$ DFMT $=$ Desossa quente marinado com TPP/NaCl 


\subsection{Condições experimentais}

\subsubsection{Local de abate}

Os animais foram abatidos na Planta Piloto do Centro de Tecnologia de Carnes do ITAL em Campinas/SP.

\subsubsection{Insensibilização dos animais}

A insensibilização dos animais foi realizada com uma pistola atordoadora pneumática, marca GIL, modelo MGO $1300 \mathrm{LH}$.

\subsubsection{Estimulação elétrica das carcaças}

Nos animais de todos os tratamentos foi aplicada a estimulação elétrica de baixa voltagem ( $21 \mathrm{~V} / 90 \mathrm{~s})$, imediatamente após a sangria dos mesmos. Foi utilizado o estimulador elétrico da marca Jarvis, modelo BV-80.

A retirada dos músculos das carcaças submetidas à desossa a quente foi realizada aproximadamente $1 \mathrm{~h}$ após a sangria $\mathrm{e}$, nas desossadas convencionalmente, $24 \mathrm{~h}$ após a mesma.

\subsubsection{Condicionamento e resfriamento dos cortes}

Os cortes desossados a quente foram resfriados gradativamente (condicionamento), inicialmente em câmara a $25^{\circ} \mathrm{C}$ durante $15 \mathrm{~h}$, a seguir foram 
transferidos para uma câmara a $7^{\circ} \mathrm{C}$ até atingir a temperatura de $15^{\circ} \mathrm{C}$ no centro da peça, quando então foram colocados a $0^{\circ} \mathrm{C}$ até atingir a temperatura interna de $5^{\circ} \mathrm{C}$, quando foram submetidos à marinação. Estas temperaturas foram monitoradas pelo registrador de temperatura marca Novus modelo ISO 485-1, através do termopar tipo PT 100.

As carcaças da desossa convencional foram resfriadas em câmara a $0 \pm 2^{\circ} \mathrm{C}$ por 24 horas e posteriormente desossadas.

\subsubsection{Marinação}

O processo de marinação foi realizado por injeção no músculo Biceps femoris (BF), onde utilizou-se uma injetora de agulhas (Linggaard mod 500, 421/min), com nível de injeção alvo de 20\% (Figura 2).

A composição das salmouras utilizadas nos processos de marinação são apresentadas na Tabela 1.

Tabela 1. Composição das salmouras utilizadas no processo de marinação do músculo Bíceps femoris

Composição

$\mathrm{CaCl}_{2} / \mathrm{NaCl} \quad \mathrm{TPP} / \mathrm{NaCl}$

$(\%)$

Água

96,0

95,8

Cloreto de sódio (sal comercial)

2,4

2,4

Tripolifosfato de sódio KENA $27^{\circledR}$ Rhodia Food

$-\quad 1,8$

Cloreto de Cálcio (150mM)Ecibra ${ }^{\circledR}$

1,6

Após a marinação os cortes aguardaram 30 minutos para o processo de gotejamento (Figura 3) e após foram colocados em filme de polietileno e 
armazenados durante 20 horas a $0^{\circ} \mathrm{C}$ para permitir distribuição uniforme da salmoura no músculo.

\subsubsection{Porcionamento dos músculos, embalagem, congelamento e armazenamento}

Os cortes marinados e controle do músculo Biceps femoris, foram divididos em 3 porções conforme a Figura 2: i) uma destinada às avaliações instrumentais e sensorial de equipe treinada, ii) outra para avaliações de textura e, iii) a terceira para avaliações físico e químicas. Em seguida, as porções foram embaladas a vácuo em filme termoencolhível não permeável ao oxigênio (Cryovac ${ }^{\circledR}$ ) e congeladas sob nitrogênio líquido em armário criogênico, marca CRYO CHEM, modelo BF 100.

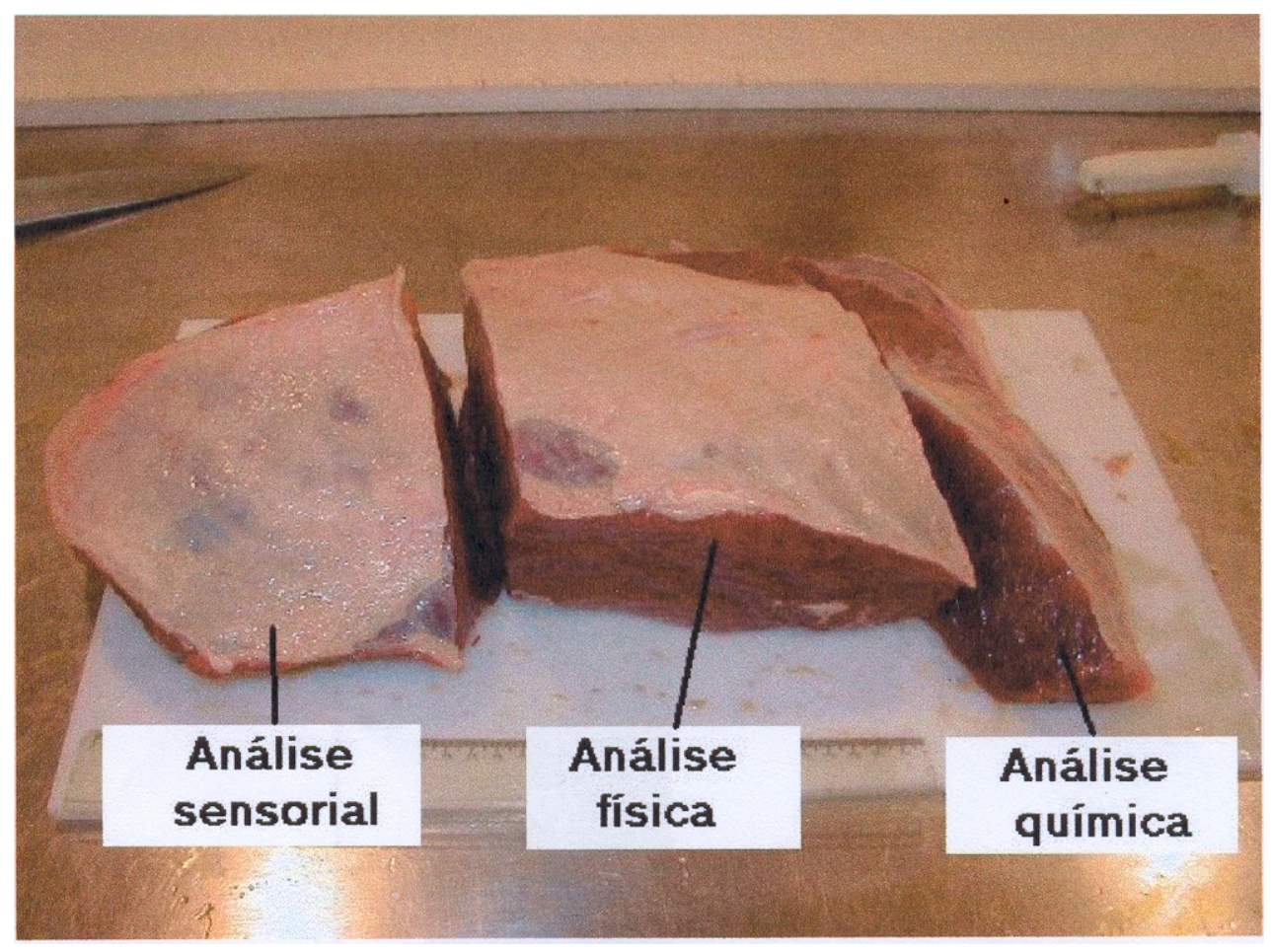

Figura 2 - Porcionamento do corte Bíceps femoris para as análises 
Os cortes foram colocados em caixas de papelão parafinado interiormente, e tampados (caixas tipo exportação $15 \mathrm{~kg}$ com dimensões $536 \times 235 \times 162 \mathrm{~mm}$ ) e armazenadas à $-18^{\circ} \mathrm{C}$ até a realização das análises.

\subsubsection{Descongelamento}

Os cortes destinados as avaliações instrumentais e químicas foram descongelados a temperatura de $4^{\circ} \mathrm{C}$ por 24 horas.

\subsubsection{Corte em bifes}

Após o descongelamento, foi retirada a película superficial de tecido conjuntivo das porções de carne, as quais foram então cortadas na forma de bifes de 2,54cm de espessura (AMSA, 1995). As amostras foram fatiadas em fatiadora de bifes Skymsem modelo FC 350 e grelhadas a temperatura de $150^{\circ} \mathrm{C}$ em chapa elétrica Sirman, modelo PDL. A temperatura interna dos bifes foi de $72^{\circ}-74^{\circ} \mathrm{C}$ e monitorada pelo termômetro marca Novus modelo 51 , com termopar tipo $\mathrm{K}$.

\subsubsection{Cozimento e preparo geral das amostras}

As amostras de bife foram grelhadas em chapa elétrica marca SIRMAN, modelo PDL, até atingirem a temperatura interna de $72-74^{\circ} \mathrm{C}$. A temperatura interna foi avaliada com termopar de haste de $15 \mathrm{~cm}$, marca NOVUS, modelo 51, tipo K. Após resfriamento a temperatura interna de $40^{\circ} \mathrm{C}$, 
as amostras de bifes foram cortadas na forma de cubos de $1,27 \mathrm{~cm}$, para avaliação sensorial de equipe treinada.

As condições utilizadas na cocção das amostras de carne foram as preconizadas pela (AMSAC, 1991).

\subsection{Respostas experimentais}

\subsubsection{Caracterização da matéria-prima}

Determinações dos teores de umidade, proteína, gordura, cinzas e cloretos dos músculos foram realizadas segundo metodologia descrita por (Cuniff,1998), após descongelamento das amostras. Nesta ocasião, determinação do teor de colágeno foi realizada pelo método descrito por (Hill, 1966).

\subsubsection{Perdas de peso no descongelamento}

Foi determinada a perda de peso no descongelamento e o resultado expresso em porcentagem do peso total do corte.

\subsubsection{Perdas de peso no cozimento}

Foi determinada a perda de peso por cozimento através da razão obtida entre os pesos das amostras antes e após a cocção. O resultado foi expresso em porcentagem (Honikel, 1987). 


\subsection{4 pH e cor}

As medidas foram realizadas após a desossa, após a marinação e após descongelamento. A leitura foi realizada com eletrodo de punção acoplado em potenciômetro devidamente calibrado, marca Digimed, modelo DM2.

Para a determinação de cor foi usado o espectrofotômetro MINOLTA modelo $\mathrm{Cm}$ 508-d, para leitura dos parâmetros $L^{*}$ (luminosidade), a* (intensidade de vermelho) e $\mathrm{b}^{*}$ (intensidade de amarelo) conforme especificações CIE (Comission Internacionale d'le Ecleraige), citado em (MacDougall, 1994).

Cada unidade experimental do corte Biceps femoris foi medida antes e após marinação e após descongelamento. Essas medições foram realizadas após 30 minutos de exposição ao oxigênio.

\subsubsection{Avaliação da maciez}

A avaliação da maciez foi realizada através de métodos objetivos (análise da força de cisalhamento) e métodos subjetivos (análise sensorial).

\subsubsection{Determinação da força de cisalhamento}

A força de cisalhamento foi avaliada através do texturômetro TA-XT 2i, equipado com o dispositivo WB. O equipamento foi calibrado com peso padrão de $5 \mathrm{~kg}$ com padrão rastreável. A velocidade de descida do dispositivo foi de 200 $\mathrm{mm} / \mathrm{min}$ (AMSA, 1995). Cada unidade experimental foi grelhada, resfriada à temperatura ambiente e retirados de 6 a 10 amostras cilíndricas de $1,27 \mathrm{~cm}$ de 
diâmetro. A determinação foi realizada $24 \mathrm{~h}$ depois sob temperatura ambiente, sendo considerado como valor final a média das leituras expressa em kgf.

\subsubsection{Análise sensorial}

A análise sensorial foi conduzida utilizando-se equipe treinada em teste quantitativo para os atributos de maciez e suculência utilizando uma escala linear não estruturada ancorada em 3 pontos de referência . Para a avaliação do sabor salgado, metálico, amargo e de sabão utilizou-se uma escala de categoria verbal de 7 pontos conforme a Figura 3.

O teste foi conduzido em laboratório com equipe de 10 provadores, foi utilizada iluminação verde na área das cabines para minimizar as avaliações sem tendências dos atributos em estudo. As amostras foram grelhadas conforme especificado no item 3.5.9. As amostras foram cortadas em cubos de $1,27 \mathrm{~cm} \times 1,27 \mathrm{~cm} \times$ altura do bife ( sem crostas), mantidas aquecidas a em estufa da marca Metalúrgica Borges a temperatura de $40^{\circ} \mathrm{C}$. A apresentação das amostras foi monádica, codificadas com números de 3 dígitos escolhidos de forma casualizada. Foram servidas 4 amostras por sessão e o delineamento estatístico foi o de blocos completos com relação aos provadores. Os dados foram coletados utilizando-se sistema informatizado da COMPUSENSE INC. Canadá, CSA, versão 4.2 . 


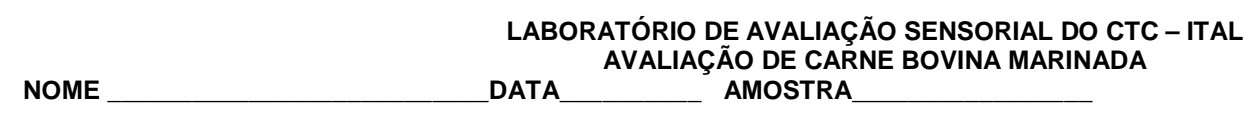

Por favor, prove a amostra e avalie quanto à maciez, suculência e sabor de acordo com as escalas.

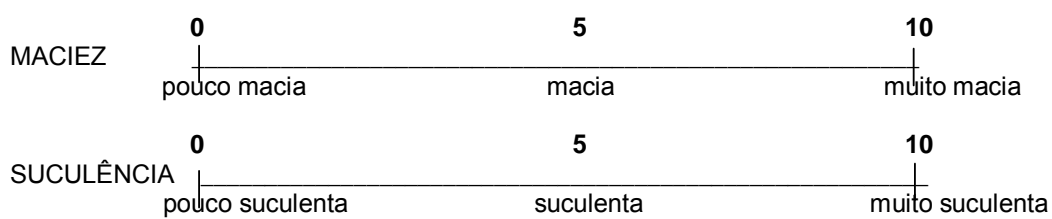

SABOR de Salgado (S) Metálico (M) Amargo (A) Sabão ( Sb)

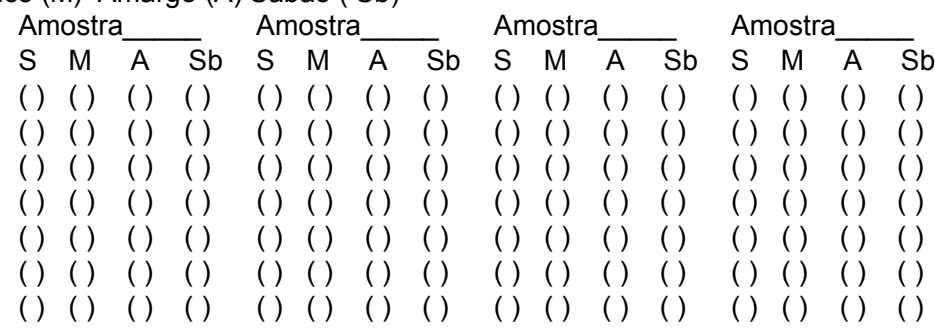

Comentários

Figura 3 - Ficha de avaliação sensorial de provador treinado

\subsubsection{Análise estatística dos dados}

Os resultados experimentais obtidos foram submetidos a análise de variância (ANOVA) e teste de Tukey com nível de significância de 5\%.

Os resultados foram tratados como dois experimentos fatoriais 2 (tipo de desossa) X 3 (tipo de salmoura para marinação) no corte estudado.

$O$ efeito dos diferentes fatores testados, bem como as interações nos parâmetros físicos e químicos foi determinado através de ANOVA, utilizando-se o teste de Tukey com nível de significância de $5 \%$. 


\section{RESULTADOS E DISCUSSÃO}

\subsection{Avaliação química}

\subsubsection{Umidade, gordura e cinzas}

Na Tabela 2 são apresentados os resultados das análises químicas de umidade, gordura e cinzas no músculo Biceps femoris submetidos a diferentes condições de desossa a frio (DF) e a quente (DQ) e salmoura $\mathrm{CaCl}_{2} / \mathrm{NaCl}(\mathrm{MC})$, $\mathrm{TPP} / \mathrm{NaCl}(\mathrm{MT})$ e não marinado (NM) e as interações entre as variáveis.

O tipo de desossa não apresentou efeito significativo $(P>0,05)$ na característica umidade, sendo o valor de umidade para a desossa a quente (DQ) de $76,7 \%$ e para a desossa a frio (DF) de $76,6 \%$. O tipo de salmoura apresentou significância $(P \leq 0,05)$ na análise de umidade, o tratamento não marinado (NM) apresentou menores valores com média de 75,9\% em relação aos tratamentos marinados $\mathrm{CaCl}_{2} / \mathrm{NaCl}(\mathrm{MC}$ ) e TTP/NaCl (MT), com valores de $76,8 \%$ e $77,2 \%$ respectivamente.

A relação umidade está ligada a proporção do nível de injeção, a salmoura MT apresentou maiores níveis de injeção e resultou em valores maiores de umidade.

As condições de desossa e salmoura não apresentaram efeito significativo $(P>0,05)$ no teor de gordura conforme Tabela 2 . 
As condições de salmoura afetaram significativamente $(P \leq 0,05)$ os teores de cinzas (Tabela 2). O tipo de tratamento influenciou nos valores de cinzas $(P>0,05)$, sendo maior para os tratamentos marinados.

Tabela 2. Efeito da desossa e do tipo de salmoura nas avaliações de umidade, gordura e cinzas do músculo Biceps femoris

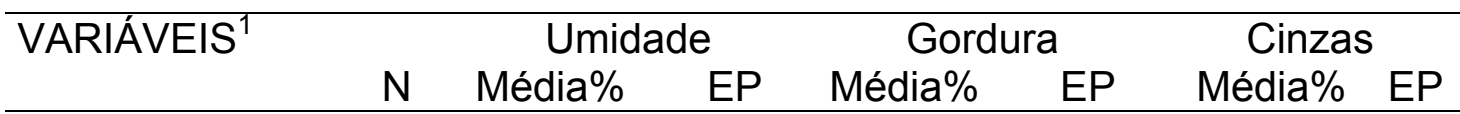

\section{EFEITO}

DESOSSA

$\mathrm{DQ}$

DF

TIPO

SALMOURA

NM

MC

MT

INTERAÇÃO

$N M X D Q$

NM X DF

$M C \times D Q$

$M C \times D F$

$M T \times D Q$

MT X DF
18

18

$0,7 \quad 2,3^{\mathrm{a}}$

$0,2 \quad 2,1^{a}$

0,1

$1,8^{\mathrm{a}}$

$1,9^{\mathrm{a}}$

0,1

$76,6^{\mathrm{a}}$

$2,1^{\text {a }}$

0,1

0,2 (a) 
A marinação promoveu entrada tanto de água como de íons da salmoura na carne, havendo portanto elevação dos teores de umidade e cinzas entre os tratamentos marinados.

A elevação da umidade por efeito da diluição reduziu o teor de proteína nos cortes. O nível de injeção está relacionado ao teor de umidade, mas segundo (Boles \& Shand, 2001) esta correlação é inconsistente, provavelmente devido a variação do teor de gordura presente no corte.

A interação da variável desossa e salmoura não foi estatisticamente significativa (Tabela11).

$\mathrm{Na}$ análise de interação entre os tratamentos houve diferença significativa do atributo umidade. Os tratamentos marinados apresentaram valores maiores para MT $\times$ DF, enquanto o menor valor foi para o tratamento $\mathrm{NM} \times$ DF. O tratamento NM $\times$ DF é considerado amostra controle e representa o corte comercial. O tratamento NM x DQ não diferenciou da amostra marinada MC $\times$ DQ e MC x DF.

Para a análise de gordura não houve interação significativa entre os tratamentos. Os valores médios se encontraram entre 2,0\% para MC x DF e $2,4 \%$ para MT x DF.

No estudo das interações para a análise de cinzas existe diferenças significativas $(P>0,05)$ entre as amostras NM $\times$ DQ e NM X DF com médias de $1,1 \%$ contra valores de 2,2 a $2,4 \%$ para as demais interações. A diferença percentual entre o tratamento NM $x$ DF e os tratamentos MC $\times D Q$ e DF e MT $x$ DQ e DF indicou aumento de $100 \%$ no valor final, devido a presença de sais na salmoura.

Os tratamentos marinados apresentaram maior teor de cinzas em relação ao NM, independente do tipo de desossa. 


\subsubsection{Proteína e colágeno}

Com relação a análise de proteína, os resultados são mostrados na Tabela 3 e indicam que não houve diferenças significativas $(p \leq 0,05)$ pelo tipo de desossa. A marinação influenciou estatisticamente no valor de proteína do corte. O músculo Biceps femoris submetido ao tratamento NM apresentou maior valor médio de $20,0 \%$ e o tratamento MC de $17,6 \%$.

Tabela 3. Efeito da desossa e do tipo de salmoura nos teores de proteína e colágeno do músculo Biceps femoris

\begin{tabular}{|c|c|c|c|c|c|}
\hline \multirow[t]{2}{*}{ VARIÁVEIS $^{1}$} & \multirow[b]{2}{*}{$\mathrm{N}$} & \multicolumn{2}{|c|}{ Proteína } & \multicolumn{2}{|c|}{ Colágeno } \\
\hline & & Média\% & EP & Média\% & EP \\
\hline \multicolumn{6}{|l|}{ EFEITO } \\
\hline \multicolumn{6}{|l|}{ DESOSSA } \\
\hline $\mathrm{DQ}$ & 18 & $19,4^{\mathrm{a}}$ & 0,5 & $1,2^{\mathrm{a}}$ & 0,1 \\
\hline DF & 18 & $18,5^{\mathrm{a}}$ & 0,5 & $1,1^{\mathrm{b}}$ & 0,09 \\
\hline \multicolumn{6}{|l|}{ TIPO } \\
\hline \multicolumn{6}{|l|}{ SALMOURA } \\
\hline NM & 12 & $20,0^{\mathrm{a}}$ & 0,7 & $1,4^{\mathrm{a}}$ & 0,1 \\
\hline MC & 12 & $19,2^{\mathrm{ab}}$ & 0,7 & $1,0^{\mathrm{b}}$ & 0,1 \\
\hline MT & 12 & $17,6^{b}$ & 0,4 & $1,0^{\mathrm{b}}$ & 0,07 \\
\hline \multicolumn{6}{|l|}{ INTERAÇÃO } \\
\hline NM X DQ & 6 & $20,7^{\mathrm{a}}$ & 0,8 & $1,5^{\mathrm{a}}$ & 0,2 \\
\hline NM X DF & 6 & $19,3^{\mathrm{a}}$ & 1,3 & $1,3^{\mathrm{ab}}$ & 0,2 \\
\hline$M C \times D Q$ & 6 & $19,7^{\mathrm{a}}$ & 1,0 & $1,0^{\mathrm{b}}$ & 0,2 \\
\hline MC X DF & 6 & $18,7^{\mathrm{a}}$ & 1,1 & $1,0^{\mathrm{b}}$ & 0,1 \\
\hline MT X DQ & 6 & $17,7^{\mathrm{a}}$ & 0,7 & $1,0^{b}$ & 0,1 \\
\hline MT X DF & 6 & $17,6^{\mathrm{a}}$ & 0,4 & $0,9^{b}$ & 0,08 \\
\hline
\end{tabular}

${ }^{1}$ médias na coluna com uma mesma letra sobrescrita não diferem significativamente $(P>0,05)$ pelo teste de Tukey

$\mathrm{N}=$ número de amostras do músculo $\mathrm{EP}=$ erro padrão

$D Q=$ Desossa a quente $D F=$ Desossa a frio

$\mathrm{NM}=$ Não marinado $\mathrm{MC}=$ salmoura $\mathrm{CaCl}_{2} / \mathrm{NaCl} \mathrm{MT}=$ salmoura $T P P / \mathrm{NaCl}$ 
$\mathrm{Na}$ Tabela 3 observa-se que a marinação apresentou efeito significativo $(P>0,05)$ sobre teor de colágeno. A desossa apresentou diferença de $0,1 \%$ entre os tratamentos. Provavelmente devido ao processo de limpeza, que é dificultado na desossa quente. Segundo (Taylor,1974), é impossível remover a quantidade normal de gordura e do tecido conjuntivo na $D Q$ e isto foi verificado no presente trabalho.

A marinação influenciou no teor de colágeno onde, $\mathrm{MC}$ e $\mathrm{MT}$, apresentaram valores de $1,0 \%$ de colágeno e o do tratamento NM $(1,4 \%)$.

A análise de colágeno apresentou os maiores valores para o tratamento $\mathrm{NM} \times \mathrm{DQ}$ e os menores valores para MT X DF.

A interação entre os tratamentos para o valor de proteína apresentaram as maiores médias para o tratamento $\mathrm{NM} \times \mathrm{DQ}$ de $20,7 \%$ e as menores médias para o tratamento MT x DF de 17,6\%.

$\mathrm{Na}$ interação salmoura $\mathrm{x}$ desossa não houve efeito significativo $(P>0,05)$ para as variáveis cinzas e colágeno (Tabela11).

\subsection{Avaliação de processamento}

\subsubsection{Força de cisalhamento e nível de injeção}

O resultado da avaliação de processamento no músculo Biceps femoris submetidos a diferentes condições de desossa e salmoura são apresentados na Tabela 4. 
Tabela 4. Efeito da desossa e do tipo de salmoura nas características da força de cisalhamento e nível de injeção do músculo Biceps femoris

\begin{tabular}{|c|c|c|c|c|c|}
\hline \multirow[t]{2}{*}{ VARIÁVEIS $^{1}$} & \multicolumn{3}{|c|}{$\begin{array}{c}\text { Força de } \\
\text { Cisalhamento }\left(\mathrm{kgf} / \mathrm{cm}^{2}\right)\end{array}$} & \multicolumn{2}{|c|}{ Nível de injeção (\%) } \\
\hline & $\mathrm{N}$ & Média & EP & Média & EP \\
\hline \multicolumn{6}{|l|}{$\begin{array}{l}\text { EFEITO } \\
\text { DESOSSA }\end{array}$} \\
\hline $\mathrm{DQ}$ & 18 & $4,6^{b}$ & 0,2 & $10,5^{a}$ & 2,1 \\
\hline $\mathrm{DF}$ & 18 & $5,1^{a}$ & 0,2 & $8,8^{\mathrm{b}}$ & 1,5 \\
\hline \multicolumn{6}{|l|}{ TIPO } \\
\hline NM & 12 & $5,4^{\mathrm{a}}$ & 0,3 & $0^{\mathrm{b}}$ & 0 \\
\hline $\mathrm{MC}$ & 12 & $4,9^{\mathrm{ab}}$ & 0,2 & $13,6^{a}$ & 0,8 \\
\hline MT & 12 & $4,3^{b}$ & 0,2 & $15,4^{a}$ & 1,5 \\
\hline \multicolumn{6}{|l|}{ INTERAÇÃO } \\
\hline $\mathrm{NM} \times \mathrm{DQ}$ & 6 & $4,9^{a b}$ & 0,4 & $0^{\mathrm{b}}$ & 0,0 \\
\hline NM X DF & 6 & $5,9^{\mathrm{a}}$ & 0,4 & $0^{\mathrm{b}}$ & 0,0 \\
\hline$M C \times D Q$ & 6 & $4,6^{b}$ & 0,2 & $16,0^{\mathrm{a}}$ & 0,8 \\
\hline$M C \times D F$ & 6 & $5,2^{\mathrm{ab}}$ & 0,4 & $11,3^{\mathrm{a}}$ & 0,6 \\
\hline$M T \times D Q$ & 6 & $4,3^{b}$ & 0,3 & $15,7^{\mathrm{a}}$ & 3,1 \\
\hline MT X DF & 6 & $4,3^{b}$ & 0,4 & $15,1^{a}$ & 0,5 \\
\hline
\end{tabular}

${ }^{1}$ médias na coluna com uma mesma letra sobrescrita não diferem significativamente $(P>0,05)$ pelo teste de Tukey

$\mathrm{N}=$ número de amostras do músculo $\mathrm{EP}=$ erro padrão

$D Q=$ Desossa a quente $D F=$ Desossa a frio

$\mathrm{NM}=\mathrm{Não}$ marinado $\mathrm{MC}=$ salmoura $\mathrm{CaCl}_{2} / \mathrm{NaCl} \mathrm{MT}=$ salmoura $T P P / \mathrm{NaCl}$

A desossa a marinação apresentaram efeito significativo $(P>0,05)$ na força de cisalhamento.

A força de cisalhamento entre para os cortes $D Q$ apresentou diferença significativa da DF, apresentando maiores valores para DF. Schmidt \& Keman (1974) avaliaram o efeito da DQ e a DF em músculos de bovinos e 
não encontraram diferença estatística entre os tratamentos. Para a força de cisalhamento no músculo Biceps femoris os valores foram 9,9kgf para DQ e 9,1 kgf para DF.

Dransfield (1976) relatou que a dureza medida pela força de cisalhamento é sutilmente aumentada pela $\mathrm{DQ}$. Os valores encontrados em nosso estudo foram menores e esta diferença provavelmente foi devido ao método de cocção. Estudos realizados por (Contreras, 1995), em carnes de peito de aves relataram valores maiores de força de cisalhamento em músculos $D Q$, porém estes dados não avaliaram o processo da marinação.

Existem controvérsias sobre o efeito da desossa na força de cisalhamento. Fatores como a estimulação elétrica, período de rigor da carne e método de cocção intensificam as variações dos dados.

Yu \& Lu (1986) relataram que a força de cisalhamento em músculos esternomandibulares cozidos até 6 horas pré rigor foi menor quando comparado com o processo entre 6 a 12 horas pós rigor. Entretanto, (Boles \& Shwan,1997) não encontrou diferença significativa de cozimento pré e pós rigor do músculo semimembranoso.

Para a marinação médias para os valores de força de cisalhamento foram maiores no tratamento NM e menores e, para as salmouras MC e MT. Houve diferença significativa $(P \leq 0,05)$ entre os tratamentos NM e MT. Stites et al. (1989) concluíram que injetando $10 \%$ de solução em carne bovina contendo tripolifosfato de sódio e cloreto de sódio os valores da força de cisalhamento foram menores quando comparados ao controle.

O nível de injeção entre os tratamentos marinados apresentaram diferença estatística $(P \leq 0,05)$ no tipo de salmoura. A média de valor para o tratamento MT foi $14,2 \%$ e MC de $13,6 \%$, sendo que a porcentagem definida neste trabalho foi de $15 \%$. Esta variação é decorrente da pressão do equipamento e da quantidade de salmoura. Os fosfatos aumentam a capacidade de retenção de água e o nível de injeção (Lawrence et al.,2004). 
Swift \& Berman (1959) relataram que aumentando o nível de cálcio há uma diminuição na capacidade de retenção de água (CRA) na carne bovina. Entretanto Hamm (1966) conclui que a diferença na CRA é devido ao diferencial de cátions multivalentes, quando o número de ligação aumenta a CRA diminui.

Ao analisar a interação dos dois fatores (desossa $x$ salmoura), na força de cisalhamento (Anexo1) não houve efeito significativo $(P>0,05)$. Maiores valores foram obtidos para as carnes não marinadas e desossadas a frio.

Para o nível de injeção as médias variaram de $11,3 \%$ para o tratamento MC $\times$ DF a $16 \%$ MC $\times$ DQ e para MT x DQ e DF a média foi de $15 \%$.

\subsubsection{Perda de peso no descongelamento (PPD) e perda de peso na cocção (PPC)}

$\mathrm{Na}$ Tabela 5 são apresentados os dados da perda de peso no descongelamento (PPD) e da perda de peso na cocção (PPC) do músculo Biceps femoris.

O tipo de desossa teve efeito significativo $(p \leq 0,05)$ na perda de peso no cozimento (PPC) e o tipo de salmoura na perda de peso no descongelamento (PPD) e na perda de peso na cocção (PPC).

Para o tipo de salmoura, a média de PPD foi maior nas amostras NM enquanto nos tratamentos MC e MT foram 35\% e $87 \%$ menores respectivamente. A atuação do tripolifosfato com cloreto de sódio é sinergística aumentando a capacidade de retenção de água no processo de descongelamento.

Ambos processos de marinação promoveram valores de PPD inferiores aos observadas nos tratamentos não marinados, ressaltando neste 
trabalho menores valores para a salmoura MT. O efeito do ânion fosfato contribuiu na liga e na capacidade de retenção de água (Sofos, 1986).

Tabela 5. Efeito da desossa e do tipo de salmoura na perda de peso no descongelamento (PPD) e na perda de peso na cocção do músculo Biceps femoris

\begin{tabular}{|c|c|c|c|c|c|}
\hline \multirow{2}{*}{ VARIÁVEIS $^{1}$} & \multirow[b]{2}{*}{$\bar{N}$} & \multicolumn{2}{|c|}{ PPD (\%) } & \multicolumn{2}{|c|}{ PPC (\%) } \\
\hline & & Média & EP & Média & EP \\
\hline \multicolumn{6}{|l|}{$\begin{array}{l}\text { EFEITO } \\
\text { DESOSSA }\end{array}$} \\
\hline$D Q$ & 18 & $6,9^{\mathrm{a}}$ & 0,7 & $34,4^{\mathrm{b}}$ & 0,8 \\
\hline DF & 18 & $6,5^{\mathrm{b}}$ & 0,6 & $37,2^{a}$ & 0,5 \\
\hline \multicolumn{6}{|l|}{ TIPO } \\
\hline NM & 12 & $8,8^{\mathrm{a}}$ & 0,5 & $33,9^{b}$ & 0,9 \\
\hline $\mathrm{MC}$ & 12 & $6,5^{b}$ & 0,5 & $38,1^{a}$ & 0,7 \\
\hline MT & 12 & $4,7^{b}$ & 0,9 & $35,2^{b}$ & 0,6 \\
\hline \multicolumn{6}{|l|}{ INTERAÇÃO } \\
\hline NM X DQ & 6 & $9,5^{\mathrm{a}}$ & 0,5 & $32,1^{\mathrm{c}}$ & 1,5 \\
\hline$N M \times D F$ & 6 & $8,3^{a b}$ & 0,9 & $35,7^{\mathrm{abc}}$ & 0,6 \\
\hline$M C \times D Q$ & 6 & $6,1^{a b c}$ & 0,5 & $36,7^{\mathrm{ab}}$ & 0,8 \\
\hline$M C \times D F$ & 6 & $7,1^{\mathrm{abc}}$ & 1,0 & $39,6^{a}$ & 0,9 \\
\hline MT X DQ & 6 & $5,3^{b c}$ & 1,8 & $34,3^{b c}$ & 1,1 \\
\hline MT X DF & 6 & $4,1^{\mathrm{c}}$ & 1,0 & $36,1^{\mathrm{abc}}$ & 0,4 \\
\hline
\end{tabular}

${ }^{1}$ médias na coluna com uma mesma letra sobrescrita não diferem significativamente $(P>0,05)$ pelo teste de Tukey

$\mathrm{N}=$ número de amostras do músculo $\mathrm{EP}=$ erro padrão

$D Q=$ Desossa a quente $D F=$ Desossa a frio

$\mathrm{NM}=$ Não marinado $\mathrm{MC}=$ salmoura $\mathrm{CaCl}_{2} / \mathrm{NaCl} \mathrm{MT}=$ salmoura $T P P / \mathrm{NaCl}$

Os valores de PPC para os tratamentos NM e salmoura MT não resultaram em diferenças estatísticas conforme a Tabela 5. Este estudo difere 
do encontrado por (Mcgee et al.,2003) e (Sheard et al.,1990) onde, exibiram uma diminuição na PPC quando avaliadas amostras controle $\mathrm{x}$ marinadas com tripolifosfato de sódio e cloreto de sódio.

$\mathrm{O}$ processo de marinação com $\mathrm{CaCl}_{2} / \mathrm{NaCl}$ apresentou as maiores porcentagens de PPC, o qual contradiz Boles \& Shwan (1997) que encontrou valores menores de PPC utilizando salmoura contendo $0,15 \%$ de cloreto de cálcio em músculo semimembranoso. Koohmaraie (1990) não encontrou efeito de diminuição no rendimento de cozimento com $\mathrm{CaCl}_{2}$.

Boles (2001) relatou que a PPC diminuiu consideravelmente com o aumento do nível de injeção, entretanto não foi observado em nosso estudo esta relação. $O$ tratamento com salmoura $\mathrm{CaCl}_{2} / \mathrm{NaCl}$ não apresentou perdas significativas se comparada ao controle. Chow et al. (1986) verificaram um aumento no rendimento de cozimento quando adicionado sal e fosfato em carnes bovinas.

Judge \& Aberle (1980) observaram que a infusão de cloreto de sódio em carne pré rigor aumentou a capacidade de retenção de água devido a expansão da rede miofibrilar. Murphy \& Zerby (2004) encontraram menores valores de PPC em músculo Longíssimus dorsi de ovinos, tratados com tripolifosfato e cloreto de sódio. Esta relação não foi encontrada em nossos estudos, onde não houve diferença entre o tratamento NM considerada controle e MT. A salmoura MC apresentou uma perda de $10 \%$ em relação ao NM

Segundo (Aktas et al.,2001) amostras marinadas com cloreto de cálcio retém menos água. Provavelmente devido ao ponto isoelétrico da proteína miofibrilar que quando aumenta o número de ligações, diminui a retenção de água.

Estes resultados estão em concordância com (Perez et al.,1998), onde o tratamento controle exibiu menor perda de peso que as amostras tratadas com cloreto de sódio e cloreto de cálcio. 
$\mathrm{Na}$ variável PPD a maior diferença na perda foi de $95 \%$ para NM $\mathrm{x}$ DQ e a menor de $4,1 \%$ para TPP $x$ DF.

Para a análise de PPC houve uma variação entre desossa e salmoura. Enquanto o tratamento $M C \times D Q$ perdeu 14,3\%, a mesma salmoura MT x DF perdeu $23,5 \%$. No tratamento MT $\times$ DQ a perda foi de $6,8 \%$ e MT $x$ DF foi de $12,4 \%$. Houve grande variabilidade de 7 a $23 \%$ de perda entre os resultados das interações na variável PPC.

\subsection{Avaliação sensorial}

\subsubsection{Maciez e suculência}

$\mathrm{Na}$ Tabela 6 são apresentados os resultados da avaliação sensorial em relação à maciez e suculência do músculo Biceps femoris.

O tipo de desossa influiu significativamente $(P \leq 0,05)$ na suculência enquanto a marinação influiu na maciez e suculência. A desossa a frio apresentou maiores valores para a maciez com aumento de $12,3 \%$ enquanto a suculência elevou-se em $33 \%$. Os dados estão discordantes com (Cross \& Tennent,1980) que avaliou a suculência e concordantes com (Schmidt \& Gilbert. 1970) que avaliaram a maciez e suculência de cortes do longíssimus dorsi e não encontraram diferença significativa em cortes submetidos a DQ e DF. Dransfield (1976) relatou que a DQ não afeta a maciez, suculência e sabor avaliada pela equipe sensorial. Da mesma forma (Hoes et al., 1980) estudando o efeito da marinação com fosfatos em carne suína, não encontrou efeito significativo do tipo de desossa, mas sim sobre a marinação.

Pesquisas realizadas por (Schmidt \& Keman, 1974) resultaram em valores de maciez para DQ e DF de 3,3 e 3,2 respectivamente. A suculência resultou valores de 5,3 para DQ e 5,1 para DF em cortes do Longíssimus dorsi 
Os maiores valores de maciez foram apresentados para a salmoura MT 6,9 e a suculência apresentou a mesma tendência, atingindo 6,4. Em contrapartida, os menores valores foram para o tratamento NM com atributo maciez $(4,5)$ e suculência $(4,8)$.

Tabela 6. Efeito da desossa e do tipo de salmoura na avaliação sensorial do músculo Biceps femoris

\begin{tabular}{lccccc}
\hline VARIÁVEIS $^{1}$ & \multicolumn{2}{c}{ Maciez $^{2}$ Sensorial $^{2}$} & \multicolumn{2}{c}{$\begin{array}{c}\text { Suculência } \\
\text { Sensorial }\end{array}$} \\
\hline & $\mathrm{N}$ & Média & EP & Média & EP \\
\hline EFEITO & & & & & \\
DESOSSA & & & & & \\
DQ & 30 & $5,7^{\mathrm{a}}$ & 0,3 & $4,8^{\mathrm{b}}$ & 0,3 \\
DF & 30 & $6,4^{\mathrm{a}}$ & 0,3 & $6,4^{\mathrm{a}}$ & 0,3 \\
TIPO SALMOURA & & & & & \\
NM & 20 & $4,5^{\mathrm{b}}$ & 0,3 & $4,8^{\mathrm{b}}$ & 0,2 \\
MC & 20 & $6,7^{\mathrm{a}}$ & 0,3 & $5,7^{\mathrm{a}}$ & 0,4 \\
MT & 20 & $6,9^{\mathrm{a}}$ & 0,2 & $6,4^{\mathrm{a}}$ & 0,3 \\
INTERAÇÃO & & & & & \\
NM X DQ & 10 & $4,2^{\mathrm{b}}$ & 0,5 & $3,6^{\mathrm{c}}$ & 0,4 \\
NM X DF & 10 & $4,7^{\mathrm{b}}$ & 0,4 & $6,0^{\mathrm{ab}}$ & 0,3 \\
MC X DQ & 10 & $6,4^{\mathrm{ab}}$ & 0,5 & $5,4^{\mathrm{b}}$ & 0,5 \\
MC X DF & 10 & $6,9^{\mathrm{a}}$ & 0,5 & $6,0^{\mathrm{ab}}$ & 0,5 \\
MT X DQ & 10 & $6,4^{\mathrm{ab}}$ & 0,3 & $5,4^{\mathrm{b}}$ & 0,5 \\
MT X DF & 10 & $7,5^{\mathrm{a}}$ & 0,4 & $7,3^{\mathrm{a}}$ & 0,3 \\
\hline
\end{tabular}

${ }^{1}$ médias na coluna com uma mesma letra sobrescrita não diferem significativamente $(P>0,05)$ pelo teste de Tukey

$21=$ pouco macio $\quad 5=$ macio $\quad 10=$ muito macio

${ }^{3} 1=$ pouco suculento $5=$ suculento $10=$ mais suculento

$\mathrm{N}=$ número de amostras do músculo $\mathrm{EP}=$ erro padrão

$D Q=$ Desossa a quente $D F=$ Desossa a frio

$\mathrm{NM}=$ Não marinado $\mathrm{MC}=$ salmoura $\mathrm{CaCl}_{2} / \mathrm{NaCl} \mathrm{MT}=$ salmoura $T P P / \mathrm{NaCl}$ 
Mcgee et al.(2003) avaliou bifés de músculo semimembranoso injetados com cloreto de sódio, tripolifosfato de sódio e lactato de sódio e encontrou valores para maciez de 3,24 para a amostra controle e 4,5 para a amostra injetada. No atributo suculência os valores foram 2,67 para o controle e 4,65 o injetado.

Os tratamentos marinados promoveram um aumento na maciez sensorial de $27 \%$ para a salmoura $\mathrm{CaCl}_{2} / \mathrm{NaCl}$ e $83 \%$ para a salmoura TPP/NaCl. Estes dados são consistentes como os obtidos por (Pazos et al., 2002) que se utilizou uma salmoura com $10 \%$ de injeção de cloreto de cálcio no mesmo músculo. Anjaneyulu et al.(1989) trabalhou com adição de $2 \%$ de sal e $0,3 \%$ de fosfato em carne de búfalo e avaliou um aumento nos valores de maciez.

Em experimentos realizados por (Aktas et al.,2001) usando uma salmoura de marinação com 150mM de cloreto de cálcio os valores de maciez e suculência foram maiores, de 5,2 e 5,7, respectivamente, em relação à amostra NM.

$\mathrm{Na}$ avaliação das interações desossa $\mathrm{x}$ salmoura houve efeito $(p \leq 0,05)$ no atributo suculência (Tabela 13).

O gráfico que representa a interação no atributo suculência está indicado na Figura 4.

No atributo maciez $(P \leq 0,05)$, os tratamentos mais macios foram para MT x DQ com o valor de 7,5 e MC x DF 6,9. O tratamento considerado menos macio foi NM $\times$ DQ $(4,2)$ e NM $\times$ DF $(4,7)$, porém, não diferiu dos tratamentos marinados $M C \times D Q$ e $M T \times D Q$. A avaliação da suculência seguiram a mesma tendência que os valores de maciez. A salmoura MT x DF apresentouse mais suculento, enquanto, o tratamento menos suculento foi $N M \times D Q$. Os mesmos resultados forma encontrados por (Urbain et al.,1968) que analisou cortes cozidos com polifosfatos e refletiu no aumento da maciez e suculência. 


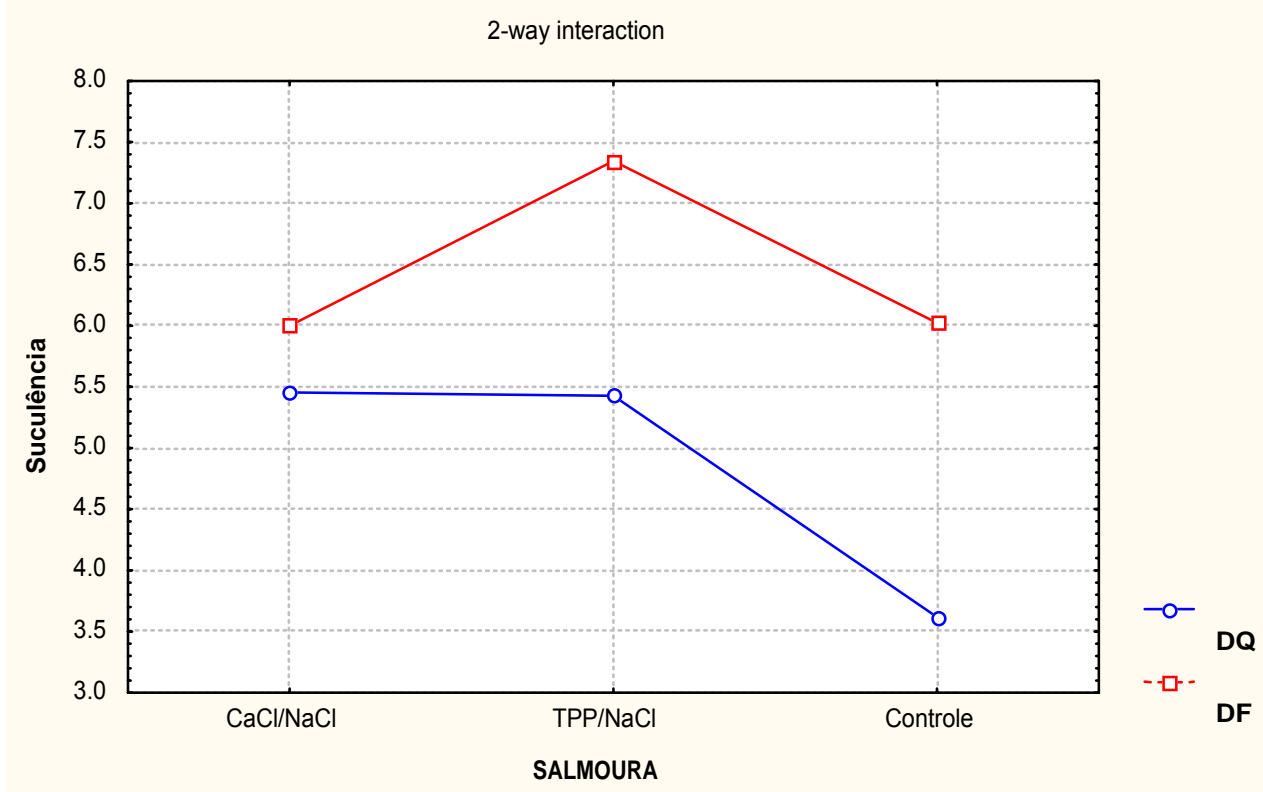

Figura 4 - Interação do efeito desossa x salmoura e sua influência na suculência no músculo Biceps femoris

\subsubsection{Sabor salgado, metálico, amargo e de sabão}

$\mathrm{Na}$ Tabela 7 são apresentados o efeito da desossa e da marinação sobre os resultados da avaliação de sabor.

Não houve efeito da desossa $(P>0,05)$ nos diferentes sabores avaliados durante a avaliação sensorial com provadores treinados. Mas, a marinação apresentou efeito $(P>0,05)$. No tratamento não marinado (NM), os valores médios foram menores para o sabor salgado, metálico, amargo e sabão em relação aos tratamentos marinados. 
Tabela 7. Efeito da desossa e do tipo de salmoura no sabor do músculo Biceps femoris

\begin{tabular}{lccccccccc}
\hline VARIÁVEIS $^{1}$ & \multicolumn{4}{c}{$\begin{array}{c}\text { Sabor } \\
\text { Salgado }\end{array}$} & \multicolumn{2}{c}{$\begin{array}{c}\text { Sabor } \\
\text { Metálico }\end{array}$} & \multicolumn{2}{c}{$\begin{array}{c}\text { Sabor } \\
\text { Amargo }\end{array}$} & \multicolumn{2}{c}{$\begin{array}{c}\text { Sabor } \\
\text { Sabão }\end{array}$} \\
\hline & $N$ & Média & EP & Média & EP & Média & EP & Média & EP \\
\hline EFEITO & & & & & & & & & \\
DESOSSA & & & & & & & & & \\
DQ & 30 & $2,6^{\mathrm{a}}$ & 0,2 & $1,7^{\mathrm{a}}$ & 0,2 & $1,6^{\mathrm{a}}$ & 0,1 & $1,6^{\mathrm{a}}$ & 0,2 \\
DF & 30 & $2,6^{\mathrm{a}}$ & 0,2 & $1,7^{\mathrm{a}}$ & 0,1 & $1,6^{\mathrm{a}}$ & 0,1 & $2,0^{\mathrm{a}}$ & 0,2 \\
& & & & & & & & & \\
TIPO & & & & & & & & & \\
SALMOURA & & & & & & & & & \\
NM & 20 & $1,1^{\mathrm{c}}$ & 0,07 & $1,4^{\mathrm{a}}$ & 0,1 & $1,4^{\mathrm{a}}$ & 0,06 & $1,3^{\mathrm{b}}$ & 0,1 \\
MC & 20 & $3,5^{\mathrm{a}}$ & 0,2 & $1,9^{\mathrm{a}}$ & 0,2 & $1,7^{\mathrm{a}}$ & 0,1 & $2,0^{\mathrm{a}}$ & 0,3 \\
MT & 20 & $3,1^{\mathrm{b}}$ & 0,1 & $1,7^{\mathrm{a}}$ & 0,2 & $1,6^{\mathrm{a}}$ & 0,1 & $2,2^{\mathrm{a}}$ & 0,1 \\
& & & & & & & & & \\
INTERAÇÃO & & & & & & & & & \\
NM X DQ & 10 & $1,1^{\mathrm{c}}$ & 0,1 & $1,4^{\mathrm{a}}$ & 0,2 & $1,4^{\mathrm{a}}$ & 0,08 & $1,2^{\mathrm{a}}$ & 0,1 \\
NM X DF & 10 & $1,1^{\mathrm{c}}$ & 0,1 & $1,4^{\mathrm{a}}$ & 0,1 & $1,5^{\mathrm{a}}$ & 0,1 & $1,2^{\mathrm{a}}$ & 0,3 \\
MC X DQ & 10 & $3,1^{\mathrm{b}}$ & 0,3 & $1,9^{\mathrm{a}}$ & 0,4 & $1,8^{\mathrm{a}}$ & 0,2 & $1,6^{\mathrm{a}}$ & 0,4 \\
MC X DF & 10 & $3,3^{\mathrm{ab}}$ & 0,2 & $1,7^{\mathrm{a}}$ & 0,2 & $1,6^{\mathrm{a}}$ & 0,2 & $2,4^{\mathrm{a}}$ & 0,4 \\
MT X DQ & 10 & $3,8^{\mathrm{a}}$ & 0,2 & $1,7^{\mathrm{a}}$ & 0,3 & $1,5^{\mathrm{a}}$ & 0,2 & $2,0^{\mathrm{a}}$ & 0,2 \\
MT X DF & 10 & $3,3^{\text {ab }}$ & 0,2 & $2,0^{\mathrm{a}}$ & 0,3 & $1,7^{\mathrm{a}}$ & 0,1 & $2,4^{\mathrm{a}}$ & 0,2 \\
\hline
\end{tabular}

${ }^{1}$ médias na coluna com uma mesma letra sobrescrita não diferem significativamente $(P>0,05)$ pelo teste de Tukey

${ }^{2} 1$ =nenhuma intensidade $2=$ ligeira intensidade $3=$ fraca intensidade

4=moderada intensidade 5 =forte intensidade $6=$ muito forte intensidade $7=$ extrema intensidade

$\mathrm{N}=$ número de amostras do músculo $\mathrm{EP}=$ erro padrão

$D Q=$ Desossa a quente $D F=$ Desossa a frio

$\mathrm{NM}=$ Não marinado $\mathrm{MC}=$ salmoura $\mathrm{CaCl}_{2} / \mathrm{NaCl} \mathrm{MT}=$ salmoura $\mathrm{TPP} / \mathrm{NaCl}$

As alterações de sabor salgado foram significativos para os cortes marinados, uma vez que os cortes não marinados não continham sal. 
A equipe treinada percebeu o sabor de salgado nas amostras tratadas com cloreto de sódio e cloreto de cálcio e cloreto de sódio e tripolifosfato de sódio. Os resultados obtidos na escala verbal encontraram-se na categoria de fraca intensidade. O nível de injeção de ambas as salmouras MC e MT foram de 13,6 e $14,2 \%$. Tratamentos realizados por (Murphy \& Zerby, 2004) com o músculo Longíssimus dorsi injetados com $20 \%$ de salmoura contendo cloreto de sódio e tripolifosfato de sódio resultaram em amostra "muito salgado" conforme respostas analisadas pela equipe sensorial.

Os sabores metálico, amargo e sabão foram claramente percebidos pela equipe sensorial. Morgan et al.(1991) relatou que os provadores descreveram os sabores metálico, amargo e de fígado para amostras injetada com $10 \%$ de $\mathrm{CaCl}_{2}$ quando comparado ao tratamento não marinado. $\mathrm{Em}$ adição ao nosso estudo, (Smith et al., 1984) avaliou músculos traseiros injetados com $10 \%$ de polifostatos e os analistas detectaram sabores metálico e de sabão, mas não houve diferença significativa $(P>0,05)$ entre os tratamentos não marinados.

$\mathrm{Na}$ avaliação das interações desossa $\mathrm{x}$ salmoura houve efeito $(P \leq 0,05)$ no atributo de sabor salgado (Tabela 13).

A representação da interação gráfica desossa x salmoura do atributo sabor salgado é indicado na Figura 5. 


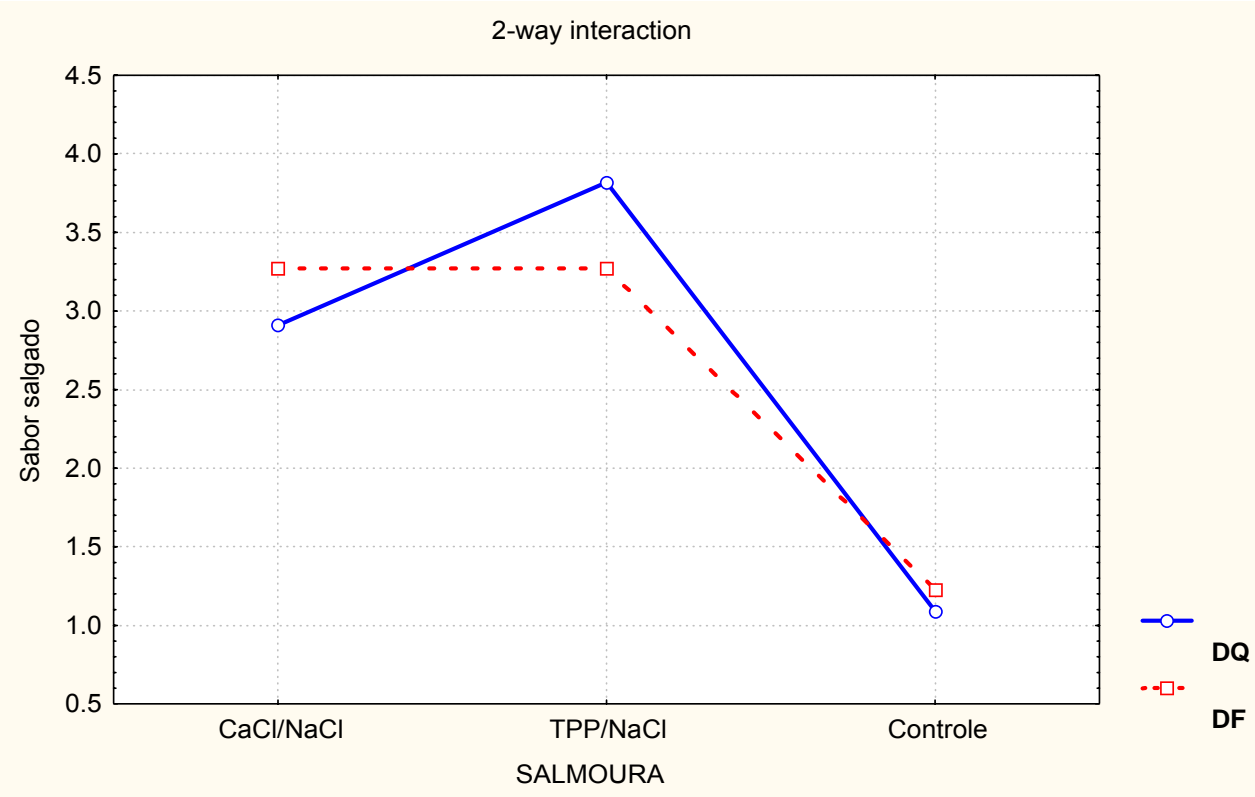

Figura 5 - Interação do efeito desossa x salmoura e sua influência na avaliação de sabor salgado no músculo Biceps femoris

No atributo salgado os tratamentos marinados resultaram em valores aproximados de 3,0 o qual é indicado na escala verbal como de fraca intensidade e o tratamento NM com valor 1,0 indicado pela escala como nenhuma intensidade.

Para o sabor de sabão, valores na escala sensorial entre ligeira e fraca intensidade para o tratamento $\mathrm{MT} \times \mathrm{DQ}$ e nenhuma intensidade para os tratamentos NM x DQ e NM x DF, foram observados.

\section{$4.4 \mathrm{pH}$}

A evolução dos valores de $\mathrm{pH}$ no músculo Biceps femoris em relação ao efeito da desossa e do tipo de salmoura são mostrados na Tabela 8. 
Tabela 8. Efeito da da desossa e o tipo de salmoura no pH do músculo Biceps femoris

\begin{tabular}{|c|c|c|c|c|c|c|c|}
\hline \multirow[t]{2}{*}{ VARIÁVEIS $^{1}$} & \multirow[b]{2}{*}{$\mathrm{N}$} & \multicolumn{2}{|c|}{$\begin{array}{l}\mathrm{pH} \text { antes } \\
\text { marinação }\end{array}$} & \multicolumn{2}{|c|}{$\begin{array}{l}\text { pH após } \\
\text { marinação }\end{array}$} & \multicolumn{2}{|c|}{$\begin{array}{c}\mathrm{pH} \text { após } \\
\text { descongelamento }\end{array}$} \\
\hline & & Média & EP & Média & EP & Média & EP \\
\hline \multicolumn{8}{|l|}{ EFEITO } \\
\hline $\mathrm{DQ}$ & 18 & $5,4^{b}$ & 0,1 & $5,6^{\mathrm{a}}$ & 0,1 & $5,4^{\mathrm{a}}$ & 0,09 \\
\hline \\
\hline SALMOURA & & & & & & & \\
\hline NM & 12 & $5,5^{\mathrm{a}}$ & 0,04 & $5,5^{\mathrm{b}}$ & 0,03 & $5,4^{b}$ & 0,01 \\
\hline MC & 12 & $5,5^{\mathrm{a}}$ & 0,03 & $5,6^{\mathrm{a}}$ & 0,05 & $5,4^{b}$ & 0,03 \\
\hline MT & 12 & $5,5^{\mathrm{a}}$ & 0,04 & $5,6^{\mathrm{a}}$ & 0,04 & $5,5^{\mathrm{a}}$ & 0,03 \\
\hline \multicolumn{8}{|l|}{ INTERAÇÃO } \\
\hline $\mathrm{NM} \times \mathrm{DQ}$ & 6 & $5,4^{\mathrm{a}}$ & 0,07 & $5,6^{\mathrm{ab}}$ & 0,04 & $5,4^{\mathrm{ab}}$ & 0,02 \\
\hline NM X DF & 6 & $5,5^{\mathrm{a}}$ & 0,05 & $5,7^{\mathrm{a}}$ & 0,05 & $5,4^{\mathrm{ab}}$ & 0,01 \\
\hline$M C \times D Q$ & 6 & $5,5^{\mathrm{a}}$ & 0,05 & $5,6^{\mathrm{ab}}$ & 0,06 & $5,4^{\mathrm{ab}}$ & 0,04 \\
\hline$M C \times D F$ & 6 & $5,5^{a}$ & 0,03 & $5,5^{a}$ & 0,07 & $5,3^{\mathrm{b}}$ & 0,05 \\
\hline MT X DQ & 6 & $5,5^{\mathrm{a}}$ & 0,08 & $5,6^{\mathrm{ab}}$ & 0,07 & $5,5^{\mathrm{a}}$ & 0,05 \\
\hline MT X DF & 6 & $5,5^{\mathrm{a}}$ & 0,04 & $5,7^{\mathrm{a}}$ & 0,03 & $5,6^{\mathrm{a}}$ & 0,03 \\
\hline
\end{tabular}

1 médias na coluna com uma mesma letra sobrescrita não diferem significativamente $(P>0,05)$ pelo teste de Tukey

$\mathrm{N}=$ número de amostras do músculo $\mathrm{EP}=$ erro padrão

$D Q=$ Desossa a quente $D F=$ Desossa a frio

$\mathrm{NM}=$ Não marinado $\mathrm{MC}=$ salmoura $\mathrm{CaCl}_{2} / \mathrm{NaCl} \mathrm{MT}=$ salmoura $\mathrm{TPP} / \mathrm{NaCl}$

Constatou-se que o efeito das condições de desossa foi estatisticamente significativo $(P \leq 0,05)$, no $\mathrm{pH}$ medido antes da marinação (Tabela 12), sendo a média dos valores de 5,4 para a DQ e 5,5 para a DF.

De forma geral, observa-se uma elevação do $\mathrm{pH}$ do corte Biceps femoris com o processo de marinação, ao comparar-se com os valores do corte "in natura". Por outro lado houve um abaixamento uniforme do $\mathrm{pH}$ medido após o descongelamento em todos os tratamentos, sugerindo um 
efeito tamponante da carne durante o período de armazenamento congelado. $\mathrm{O}$ aumento do $\mathrm{pH}$ é resultante do efeito do ânion fosfato que contribui na liga e na capacidade de retenção de água (Sofos, 1986).

Murphy \& Zerby (2004) avaliaram o efeito de uma salmoura contendo tripolifosfato (T) e outra contendo tripolifosfato e cloreto de sódio (TC) em músculos Longíssimus dorsi de ovinos no período pré rigor. O resultado da avaliação de $\mathrm{pH}$ exibiu um efeito da combinação dos aditivos no $\mathrm{pH}$ final. Houve um aumento de 0,1 e 0,2 unidade de $\mathrm{pH}$ no tratamento $\mathrm{T}$ e TC respectivamente.

O tipo de salmoura apresentou efeito significativo $(p \leq 0,05)$ no $\mathrm{pH}$ medido após a marinação e após o descongelamento (Tabela 12). Os tratamentos $\mathrm{NM}$ apresentaram valores 0,1 unidades de $\mathrm{pH}$ inferiores aos dos tratamentos marinados.

Paterson \& Parrish (1988) descreveu um efeito sinérgico entre o sal e o fosfato o qual resultou um aumento do $\mathrm{pH}$ e na capacidade de ligação de água permitindo que o tecido muscular ligue mais água na solubilização das proteínas.

Os valores de $\mathrm{pH}$ medido 24 horas post mortem ou seja antes da marinação foi similar ao encontrado por (Halloran et al., 1997) onde os cortes do Longíssimus dorsi e semimembranoso apresentaram pH normal entre 5,465,62 .

Observou-se ainda que a marinação com TPP/NaCl promoveu elevação do $\mathrm{pH}$ da carne, efeito este minimizado pelo congelamento, pelo qual promoveu abaixamento do $\mathrm{pH}$ em todos os tratamentos. Por outro lado, os músculos $\mathrm{MC}$ provenientes da $\mathrm{DQ}$, apresentaram valores de $\mathrm{pH}$ mais baixos que os demais tratamentos. $\mathrm{O}$ aumento do $\mathrm{pH}$ após a injeção de salmoura MC também foi confirmado por Hamm (1986).

A interação dos fatores de $\mathrm{pH}$ ao longo do processamento foi significativa nas etapas após a marinação e após o descongelamento (Figura 6 e 7). Os tratamento MT x DQ e MT x DF apresentaram valores de 0,1 
unidades de $\mathrm{pH}$ para os tratamentos $\mathrm{NM} \times \mathrm{DQ}, \mathrm{NM} \times \mathrm{DF}$ e $\mathrm{MC} \times \mathrm{DQ}$ e 0,2 unidades para MC x DF.

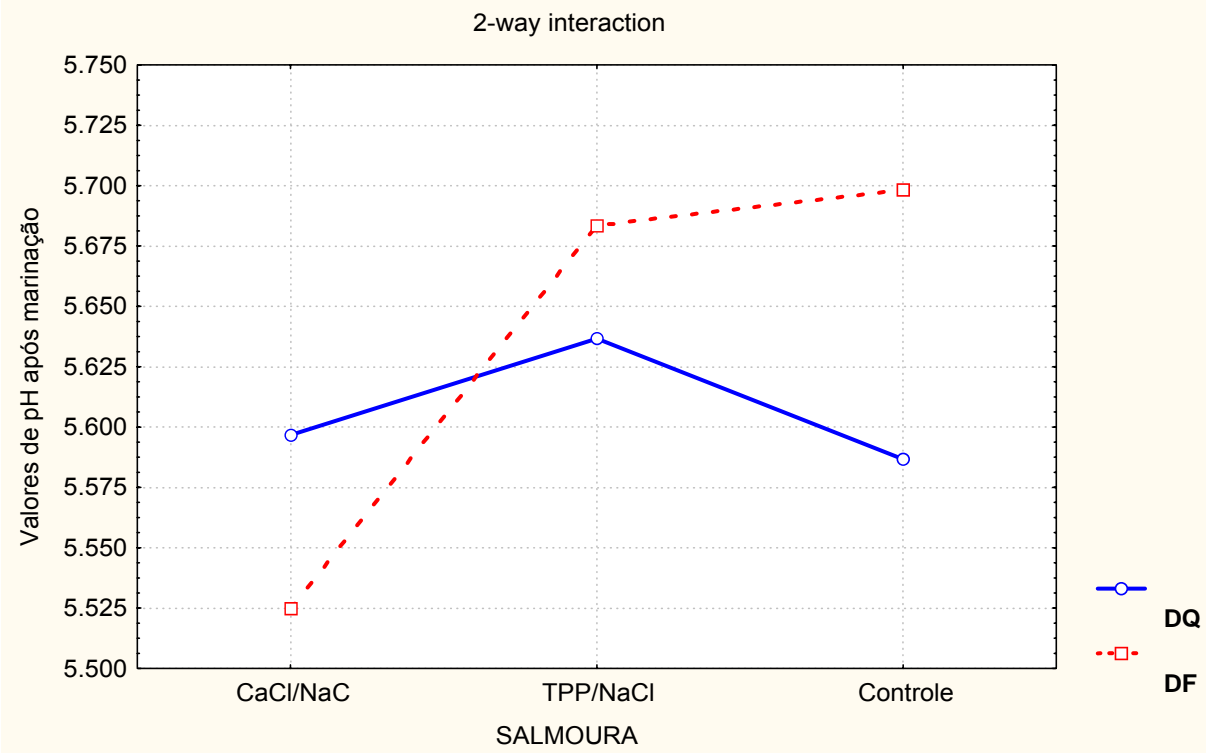

Figura 6 - Interação do efeito desossa x salmoura e sua influência na avaliação de pH após descongelamento no músculo Biceps femoris

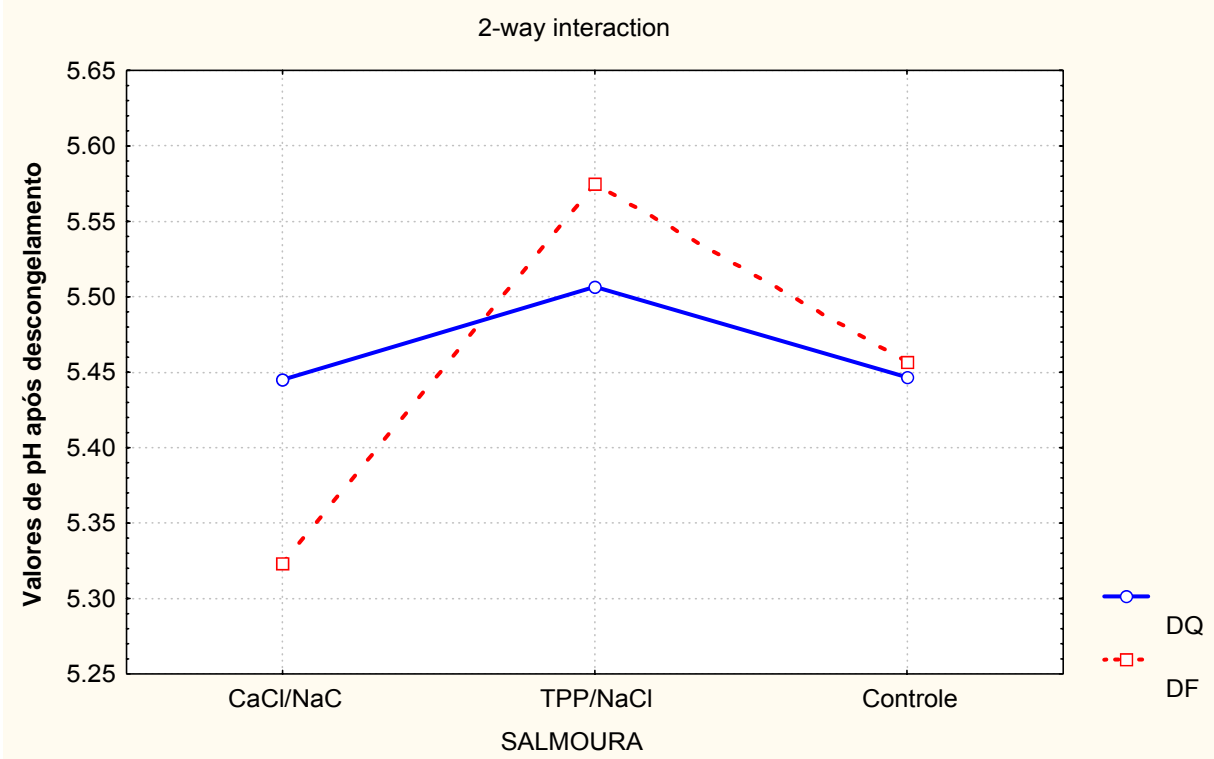

Figura 7 - Interação do efeito desossa x salmoura e sua influência no pH após descongelamento no músculo Biceps femoris 


\subsection{Avaliação da cor objetiva}

$\mathrm{Na}$ Tabela 9 são apresentados os resultados das análises de cor objetiva $\left(L^{*} a^{*} b^{*}\right)$ medidos antes e após a marinação no músculo Biceps femoris submetidos a diferentes condições de desossa (a frio e a quente) e marinação $\left(\mathrm{CaCl}_{2} / \mathrm{NaCl}\right.$, TPP/NaCl e não marinado).

$\mathrm{Na}$ Tabela 10 são apresentados os resultados das análises de cor objetiva $\left(L^{*} a^{*} b^{*}\right)$ após o descongelamento no músculo Biceps femoris.

Houve efeito significativo $(P \leq 0,05)$ da desossa no valor de $a^{*}$ e $b^{*}$ medidos após o descongelamento (Tabela 12).

Neste estudo nenhuma diferença significativa $(P>0,05)$ foi observada nos cortes não marinados DQ e DF medidos antes da marinação. Segundo (Pissula \& Tyburcy, 1996) a estimulação elétrica (EE) resulta em mudanças no brilho de músculos $\mathrm{DQ}$. Entretanto a cor do músculo $\mathrm{DQ}$ pode ser melhorada quando são realizadas etapas de condicionamento. (Griffin et al., 1992) não encontrou efeito significativo da EE e DQ na estabilidade de cor na carne bovina e (Farouk et al., 2000) relatou que o tipo de desossa não afetou significativamente a cor vermelha $\left(a^{*}\right)$ ou a cor amarela $\left(b^{*}\right)$ de bifes reestruturados.

Estudos indicam que cortes bovinos desossados a quente $\mathrm{e}$ embalados em filme permeável ao oxigênio apresentam coloração mais escura que os cortes desossados convencionalmente, porém esta alteração não foi considerada inaceitável pelos consumidores (Hunt, 1980).

A marinação apresentou efeito significativo sobre 0 teor de luminosidade $\left(L^{*}\right)$ após o marinação (Tabela 8 ). Para a salmoura MC e MT houve uma diminuição no valor de $L^{*}$ para 32,22 e 30,93 respectivamente. A amostra NM apresentou valores médios de 35,41.

O teor de vermelho $\left(a^{*}\right)$ diferiu estatisticamente quando comparado a amostra NM 17,06 à amostra MT 15,59. Houve uma diminuição na cor vermelha na salmoura com tripolifosfato de sódio e cloreto de sódio. 
Tabela 9. Efeito da desossa e do tipo de salmoura nas cor objetiva $L^{*} a^{*}$ e $b^{*}$ antes e após a marinação do músculo Biceps femoris

\begin{tabular}{|c|c|c|c|c|c|c|c|c|c|c|c|c|c|}
\hline \multirow[t]{2}{*}{ VARIÁVEIS $^{1}$} & \multirow[b]{2}{*}{$\mathrm{N}$} & \multicolumn{2}{|c|}{$\begin{array}{c}\mathrm{L}^{*} \text { antes } \\
\text { Marinação. }\end{array}$} & \multicolumn{2}{|c|}{$\begin{array}{l}\mathrm{a}^{*} \text { antes } \\
\text { marinação }\end{array}$} & \multicolumn{2}{|c|}{$\begin{array}{l}\mathrm{b}^{*} \text { antes } \\
\text { marinação }\end{array}$} & \multicolumn{2}{|c|}{$\begin{array}{l}\mathrm{L}^{*} \text { após } \\
\text { marinação }\end{array}$} & \multicolumn{2}{|c|}{$\begin{array}{c}a^{*} \text { após } \\
\text { marinação }\end{array}$} & \multicolumn{2}{|c|}{$\begin{array}{c}\mathrm{b}^{*} \text { após } \\
\text { marinação }\end{array}$} \\
\hline & & Média & EP & Média & EP & Média & EP & Média & EP & Média & EP & Média & EP \\
\hline $\begin{array}{l}\text { EFEITO } \\
\text { DESOSSA }\end{array}$ & & & & & & & & & & & & & \\
\hline $\mathrm{DQ}$ & 18 & $33,76^{a}$ & 0,3 & $18,34^{a}$ & 0,3 & $6,72^{a}$ & 0,2 & $32,68^{a}$ & 0,8 & $16,48^{a}$ & 0,4 & $5,53^{a}$ & 0,5 \\
\hline $\begin{array}{l}\text { DF } \\
\text { TIPO }\end{array}$ & 18 & $34,01^{a}$ & 0,3 & $17,82^{\mathrm{a}}$ & 0,2 & $6,15^{\mathrm{a}}$ & 0,3 & $33,03^{a}$ & 0,9 & $16,01^{\mathrm{a}}$ & 0,4 & $5,76^{a}$ & 0,7 \\
\hline SALMOURA & & & & & & & & & & & & & \\
\hline NM & 12 & $33,76^{a}$ & 0,4 & $18,11^{a}$ & 0,4 & $6,24^{a}$ & 0,4 & $35,41^{a}$ & 0,7 & $17,06^{a}$ & 0,6 & $7,60^{a}$ & 0,5 \\
\hline MC & 12 & $33,66^{a}$ & 0,3 & $18,09^{a}$ & 0,4 & $6,51^{a}$ & 0,3 & $32,22^{b}$ & 1,1 & $16,09^{\mathrm{ab}}$ & 0,4 & $4,93^{b}$ & 0,8 \\
\hline MT & 12 & $34,23^{a}$ & 0,4 & $18,04^{\mathrm{a}}$ & 0,4 & $6,55^{\mathrm{a}}$ & 0,2 & $30,93^{b}$ & 1,0 & $15,59^{b}$ & 0,6 & $4,40^{b}$ & 0,6 \\
\hline INTERAÇÃO & & & & & & & & & & & & & \\
\hline $\mathrm{NM} \times \mathrm{DQ}$ & 6 & $30,70^{a}$ & 0,4 & $18,55^{\mathrm{a}}$ & 0,5 & $6,68^{a}$ & 0,4 & $34,84^{a}$ & 0,5 & $16,66^{\mathrm{ab}}$ & 0,9 & $6,59^{\mathrm{ab}}$ & 0,4 \\
\hline NM X DF & 6 & $33,83^{a}$ & 0,8 & $17,66^{a}$ & 0,5 & $5,81^{b}$ & 0,6 & $35,98^{a}$ & 1,3 & $17,46^{\mathrm{a}}$ & 0,7 & $8,62^{a}$ & 0,7 \\
\hline$M C \times D Q$ & 6 & $33,42^{a}$ & 0,5 & $18,24^{a}$ & 0,7 & $6,84^{a}$ & 0,5 & $32,44^{a}$ & 2,1 & $16,78^{\mathrm{ab}}$ & 0,6 & $5,84^{\mathrm{ab}}$ & 1,4 \\
\hline$M C \times D F$ & 6 & $33,90^{\mathrm{a}}$ & 0,4 & $17,95^{\mathrm{a}}$ & 0,4 & $6,19^{a}$ & 0,3 & $32,01^{a}$ & 1,1 & $15,41^{\mathrm{ab}}$ & 0,4 & $4,03^{b}$ & 0,9 \\
\hline $\mathrm{MT} \times \mathrm{DQ}$ & 6 & $34,15^{\mathrm{a}}$ & 0,7 & $18,23^{a}$ & 0,7 & $6,63^{a}$ & 0,3 & $30,76^{a}$ & 0,8 & $16,01^{\mathrm{ab}}$ & 0,9 & $4,16^{b}$ & 0,5 \\
\hline MT X DF & 6 & $34,31^{a}$ & 0,4 & $17,85^{\mathrm{a}}$ & 0,5 & $6,46^{a}$ & 0,4 & $31,09^{a}$ & 1,9 & $15,18^{b}$ & 0,8 & $4,63^{b}$ & 1,2 \\
\hline
\end{tabular}

${ }^{1}$ médias na coluna com uma mesma letra sobrescrita não diferem significativamente $(P>0,05)$ pelo teste de Tukey $\mathrm{N}=$ número de amostras do músculo $\mathrm{EP}=$ erro padrão

$\mathrm{DQ}=$ Desossa a quente $\mathrm{DF}=$ Desossa a frio

$\mathrm{NM}=\mathrm{Não}$ marinado $\mathrm{MC}=$ salmoura $\mathrm{CaCl}_{2} / \mathrm{NaCl} \mathrm{MT}=$ salmoura $\mathrm{TPP} / \mathrm{NaCl}$ 
Tabela 10. Efeito da desossa e do tipo de salmoura nas cor objetiva $L^{*} a^{*}$ e $b^{*} a$ após o processo de descongelamento do músculo Biceps femoris

\begin{tabular}{|c|c|c|c|c|c|c|c|}
\hline \multirow[t]{2}{*}{ VARIÁVEIS $^{1}$} & \multirow[t]{2}{*}{$\mathrm{N}$} & \multicolumn{2}{|c|}{$\mathrm{L}^{*}$ após descongelamento } & \multicolumn{2}{|c|}{$\begin{array}{c}\mathrm{a}^{*} \text { após } \\
\text { descongelamento }\end{array}$} & \multicolumn{2}{|c|}{ b* após descongelamento } \\
\hline & & Média & EP & Média & EP & Média & EP \\
\hline $\begin{array}{l}\text { EFEITO } \\
\text { DESOSSA }\end{array}$ & & & & & & & \\
\hline $\mathrm{DQ}$ & 18 & $28,71^{\mathrm{a}}$ & 0,8 & $13,54^{\mathrm{b}}$ & 0,4 & $4,65^{b}$ & 1,3 \\
\hline $\begin{array}{l}\text { DF } \\
\text { TIPO }\end{array}$ & 18 & $27,26^{\mathrm{a}}$ & 1,3 & $15,33^{\mathrm{a}}$ & 0,7 & $6,79^{a}$ & 1,6 \\
\hline SALMOURA & & & & & & & \\
\hline NM & 12 & $31,64^{\mathrm{a}}$ & 0,9 & $15,34^{\mathrm{a}}$ & 0,5 & $6,20^{a}$ & 0,4 \\
\hline MC & 12 & $27,31^{\mathrm{b}}$ & 1,1 & $13,21^{\mathrm{a}}$ & 0,7 & $4,41^{a}$ & 1,8 \\
\hline MT & 12 & $25,01^{b}$ & 1,2 & $14,75^{\mathrm{a}}$ & 1,0 & $6,55^{a}$ & 2,5 \\
\hline INTERAÇÃO & & & & & & & \\
\hline NM X DQ & 6 & $32,29^{a}$ & 0,9 & $14,63^{\mathrm{ab}}$ & 0,7 & $6,43^{a}$ & 0,9 \\
\hline NM X DF & 6 & $30,99^{\mathrm{ab}}$ & 1,6 & $16,06^{\mathrm{a}}$ & 0,6 & $5,98^{a}$ & 0,8 \\
\hline$M C \times D Q$ & 6 & $27,98^{a b c}$ & 0,8 & $12,71^{\mathrm{b}}$ & 0,4 & $1,41^{b}$ & 0,6 \\
\hline MC X DF & 6 & $26,63^{b c}$ & 2,2 & $13,71^{\mathrm{ab}}$ & 1,4 & $7,42^{\mathrm{a}}$ & 3,3 \\
\hline MT X DQ & 6 & $25,86^{\mathrm{C}}$ & 1,2 & $13,28^{a b}$ & 0,9 & $6,13^{a}$ & 3,9 \\
\hline MT X DF & 6 & $24,16^{\mathrm{C}}$ & 2,2 & $16,21^{\mathrm{a}}$ & 1,8 & $6,97^{a}$ & 3,7 \\
\hline
\end{tabular}

${ }^{1}$ médias na coluna com uma mesma letra sobrescrita não diferem significativamente $(P>0,05)$ pelo teste de Tukey $\mathrm{N}=$ número de amostras do músculo $\mathrm{EP}=$ erro padrão

$D Q=$ Desossa a quente $D F=$ Desossa a frio

$\mathrm{NM}=\mathrm{Não}$ marinado $\mathrm{MC}=$ salmoura $\mathrm{CaCl}_{2} / \mathrm{NaCl} \mathrm{MT}=$ salmoura $\mathrm{TPP} / \mathrm{NaCl}$ 
Aktas \& Kaya (2001) encontraram valores de $L^{*}$ para a carne fresca em músculos Longíssimus dorsi de 31,6 a 36,2 . Os valores encontrados em nossos estudo antes da marinação ou seja da carne fresca foi de 33,7 concluise que o valor está em concordância com o estudo acima. A variabilidade na cor da carne pode ser explicado como as diferentes condições de alimentação que refletem no produto final (Aktas \& Kaya, 2001).

Lee et al. (1998) descreveu que a salmoura com fosfato diminuiu significativamente os valores de $L^{*}$ e $b^{*}$, mas aumentou o valor de $a^{*}$ em carne bovina. Cortes de coxão mole (semimembranosus) foram submetidos a injeção (10\%) com salmoura elaborada para resultar em um produto final contendo $0,4 \%$ de cloreto de sódio e $0,4 \%$ de fosfato, revelaram que os cortes injetados ("enhanced") forneceram bifes mais macios, suculentos e salgados que os controles; por outro lado, a injeção apresentou efeito negativo sobre a cor após dois dias de exposição sob refrigeração a $4^{\circ} \mathrm{C}$, pois houve escurecimento e descoloração (Boles \& Shand, 2001).

Houve diferença significativa na interação desossa $x$ salmoura na cor $b^{*}$ após a marinação (Figura 8) e na cor b* após o descongelamento (Figura 9).

A cor vermelha $\left(a^{*}\right)$ sofreu redução de $15 \%$ no tratamento MT $\times$ DF em relação $\mathrm{NM} \times \mathrm{DF}$ e a cor amarela $\left(\mathrm{b}^{*}\right)$ diminuiu $50 \% \mathrm{MC} \times \mathrm{DQ}, 113 \% \mathrm{MC} \times \mathrm{DF}$, $107 \%$ MT x DQ e 126\% MT x DF. As formas de desossa também sofreram redução da cor ao longo do processo de marinação. Farouk (2000) relatou que o processo de congelamento não afetou a cor vermelho $\left(a^{*}\right)$ de bifes reestruturados, mas o músculo pré-rigor adicionado de sal produziu efeito significativo na cor vermelha. Diversos trabalhos relatam o escurecimento atribuído ao cloreto de sódio (Mollins et al., 1987).

No valor de $L^{*}$ após descongelamento o tratamento $\mathrm{NM} \times \mathrm{DQ}$ sofreu aumento de $4 \%$ e os demais redução de 11 a $28 \%$. Na avaliação da cor ao longo do processamento houve uma redução de $L^{*}$, $a^{*}$ e $b^{*}$ nas amostras marinadas. Segundo (Aktas \& Kaya, 2001) o uso de $2 \%$ de cloreto de sódio 
causou aumento da luminosidade e manteve a intensidade de vermelho $\left(a^{*}\right)$ e amarelo $\left(b^{*}\right)$ quando comparou-se com amostra controle.

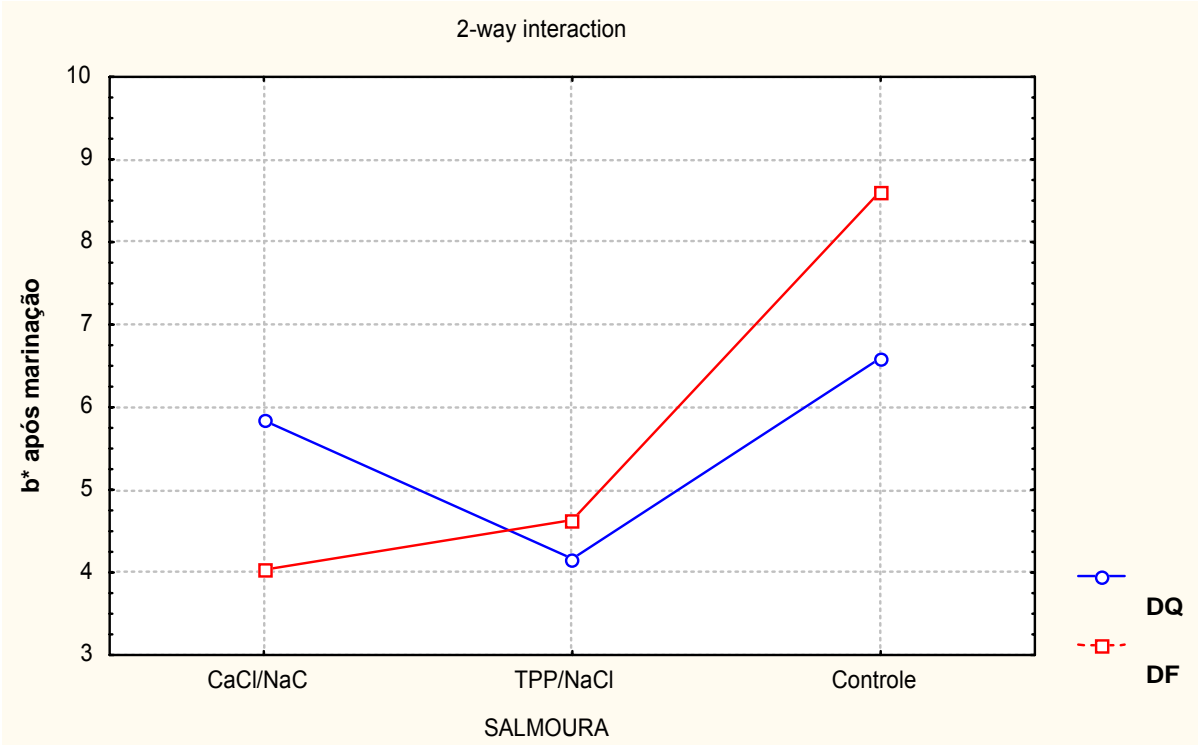

Figura 8 - Interação do efeito desossa x salmoura e sua influência na avaliação de $b^{*}$ após marinação no músculo Biceps femoris

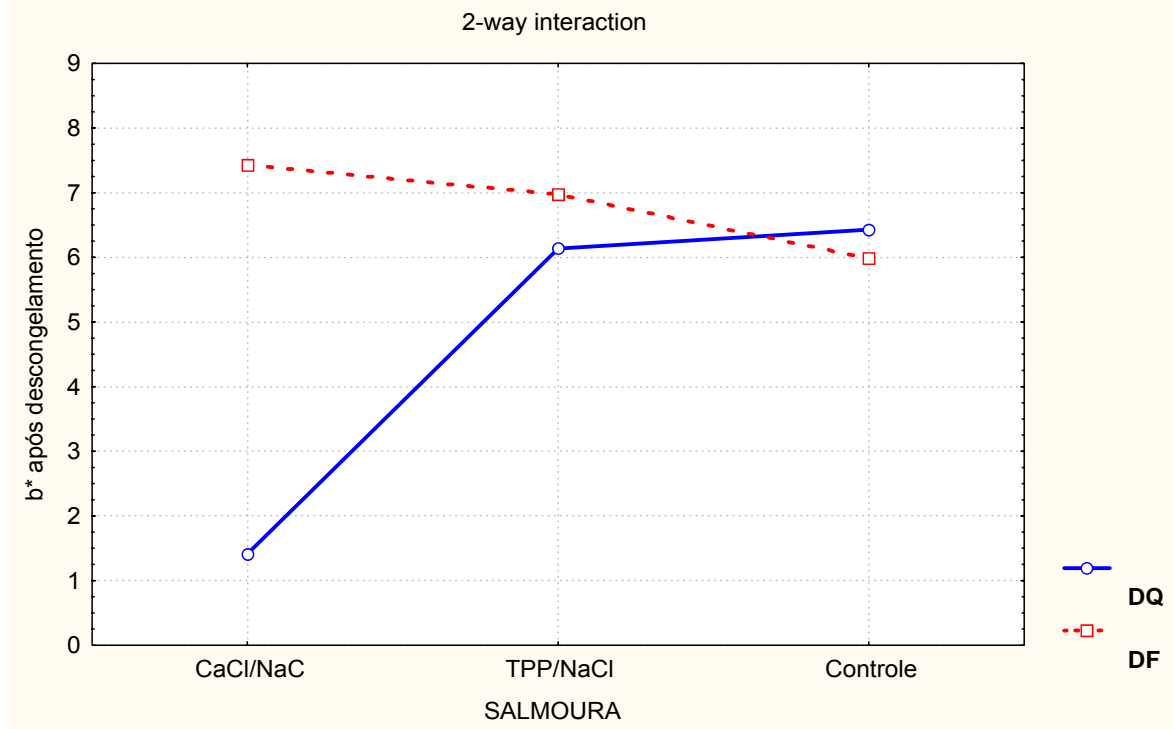

Figura 9 - Interação do efeito desossa x salmoura e sua influência na avaliação de $b^{*}$ após descongelamento no músculo Biceps femoris 


\section{CONCLUSÕES}

A marinação com tripolifosfato de sódio e cloreto de cálcio associado a desossa a quente promoveram alterações positivas sobre a maciez e suculência do músculo Biceps femoris e, constitui em uma nova tecnologia a ser utilizada pela indústria da carne.

A desossa a quente reduziu a força de cisalhamento e a perda de peso na cocção. Afetou a cor diminuindo a intensidade da cor vermelha.

A desossa a quente do músculo Biceps femoris submetido a diferentes temperaturas de acondicionamento resultaram em músculos similares ao desossado a frio e favoráveis ao processo de marinação.

O processo de marinação afetou as características químicas da carne fresca. O teor de cinzas e umidade foram as características afetadas e poderiam definir se uma carne foi marinada ou não.

O processo de marinação reduziu favoravelmente a forca de cisalhamento, a perda de peso no descongelamento e perda de peso na cocção.

O sabor não foi influenciado negativamente pela marinação.

Houve alterações negativas da marinação sobre a cor da carne, tornando-a mais escura e menos vermelha. 
ANEXOS 
Tabela 11. Valores de $\mathrm{F}$ e respectivos níveis de significância $(P)$ associados ao teste ANOVA dos efeitos de desossa e salmoura sobre as variáveis químicas e de processamento do músculo Biceps femoris

\begin{tabular}{lcccccc} 
Variáveis & \multicolumn{7}{c}{ Efeitos principais } \\
\cline { 2 - 7 } & \multicolumn{7}{c}{ Desossa } & \multicolumn{2}{c}{ Salmoura } & \multicolumn{2}{c}{$\begin{array}{c}\text { Desossa } x \\
\text { Salmoura }\end{array}$} \\
\cline { 2 - 7 } & \multicolumn{7}{c}{$P$} & $\mathrm{~F}$ & $P$ & $\mathrm{~F}$ & $P$ \\
\hline Umidade & 0,04 & 0,84 & 8,82 & $<0,01$ & 1,37 & 0,27 \\
Gordura & 0,56 & 0,46 & 0,15 & 0,85 & 0,20 & 0,81 \\
Cinzas & 1,06 & 0,31 & 86,09 & $<0,01$ & 0,24 & 0,78 \\
Proteína & 1,66 & 0,21 & 4,69 & 0,02 & 0,32 & 0,73 \\
Colágeno & 3,81 & 0,06 & 17,04 & $<0,01$ & 0,52 & 0,60 \\
Força cisalhamento & 9,33 & $<0,01$ & 13,45 & $<0,01$ & 2,45 & 0,10 \\
Nível de injeção & 3,48 & 0,07 & 105,76 & $<0,01$ & 2,43 & 0,11 \\
PPD & 0,59 & 0,45 & 15,83 & $<0,01$ & 1,41 & 0,26 \\
PPC & 20,80 & $<0,01$ & 17,06 & $<0,01$ & 0,73 & 0,49 \\
\hline
\end{tabular}


Tabela 12. Valores de $\mathrm{F}$ e respectivos níveis de significância (p) associados ao teste ANOVA dos efeitos de desossa e salmoura sobre as variáveis de $\mathrm{pH}$ e cor do músculo Biceps femoris

\begin{tabular}{|c|c|c|c|c|c|c|}
\hline \multirow[t]{3}{*}{ Variáveis } & \multicolumn{6}{|c|}{ Efeitos principais } \\
\hline & \multicolumn{2}{|c|}{ Desossa } & \multicolumn{2}{|c|}{ Salmoura } & \multicolumn{2}{|c|}{$\begin{array}{l}\text { Desossa } x \\
\text { Salmoura }\end{array}$} \\
\hline & $\mathrm{F}$ & $P$ & $\mathrm{~F}$ & $P$ & $\mathrm{~F}$ & $P$ \\
\hline pH antes marinação & 5,58 & 0,02 & 1,41 & 0,26 & 1,18 & 0,32 \\
\hline pH após marinação & 1,03 & 0,32 & 4,59 & 0,02 & 3,54 & 0,04 \\
\hline $\begin{array}{l}\text { pH após } \\
\text { descongelamento }\end{array}$ & 0,30 & 0,59 & 11,73 & $<0,01$ & 4,50 & 0,02 \\
\hline$L^{*}$ antes marinação & 0,38 & 0,54 & 0,72 & 0,49 & 0,08 & 0,92 \\
\hline$a^{*}$ antes marinação & 1,64 & 0,21 & 0,01 & 0,98 & 0,22 & 0,80 \\
\hline $\mathrm{b}^{*}$ antes marinação & 6,19 & 0,02 & 0,70 & 0,50 & 0,81 & 0,45 \\
\hline L* após marinação & 0,11 & 0,73 & 6,67 & $<0,01$ & 0,19 & 0,82 \\
\hline a* após marinação & 1,26 & 0,27 & 4,27 & 0,02 & 2,47 & 0,10 \\
\hline b* após marinação & 0,10 & 0,75 & 7,52 & $<0,01$ & 4,14 & 0,03 \\
\hline $\begin{array}{l}L^{*} \text { após } \\
\text { descongelamento }\end{array}$ & 4,26 & 0,052 & 30,67 & $<0,01$ & 0,03 & 0,96 \\
\hline $\begin{array}{l}a^{*} \text { após } \\
\text { descongelamento }\end{array}$ & 8,15 & $<0,01$ & 4,14 & 0,02 & 0,87 & 0,43 \\
\hline $\begin{array}{l}\mathrm{b}^{*} \text { após } \\
\text { descongelamento }\end{array}$ & 30,00 & $<0,01$ & 11,53 & $<0,01$ & 25,71 & $<0,01$ \\
\hline
\end{tabular}


Tabela 13. Valores de $F$ e respectivos níveis de significância $(p)$ associados ao teste ANOVA dos efeitos de desossa e salmoura sobre os parâmetros de avaliação sensorial do músculo Biceps femoris

\begin{tabular}{lccccccc}
\hline & \multicolumn{7}{c}{ Efeitos principais } \\
\cline { 2 - 8 } Variáveis & \multicolumn{2}{c}{ Desossa } & \multicolumn{3}{c}{ Salmoura } & \multicolumn{3}{c}{$\begin{array}{c}\text { Salmoura } \\
\text { Desossa }\end{array}$} \\
\cline { 2 - 8 } & $\mathrm{F}$ & $\mathrm{p}$ & $\mathrm{F}$ & $\mathrm{p}$ & $\mathrm{F}$ & $\mathrm{p}$ \\
\hline Maciez & 3,24 & 0,07 & 16,55 & $<0,01$ & 0,22 & 0,79 \\
Suculência & 32,82 & $<0,01$ & 10,27 & $<0,01$ & 3,86 & 0,02 \\
Sabor salgado & 0,02 & 0,88 & 195,1 & $<0,01$ & 4,22 & $<0,01$ \\
Sabor metálico & 0,07 & 0,79 & 3,11 & 0,07 & 0,02 & 0,97 \\
Sabor amargo & 0,04 & 0,84 & 1,09 & 0,35 & 0,51 & 0,61 \\
Sabor de sabão & 2,6 & 0,11 & 5,45 & $<0,01$ & 0,95 & 0,39 \\
\hline
\end{tabular}




\section{REFERÊNCIAS BIBLIOGRÁFICAS}

\section{AMERICAN MEAT SCIENCE ASSOCIATION COMMITTEE (AMSAC).}

Guideliness for meat color evaluation. In: ANNUAL RECIPROCAL MEAT CONFERENCE, 44., Manhattan,1991. Proceedings. Manhattan: AMSAC, 1991. 17-19p.

AMERICAN MEAT SCIENCE ASSOCIATION (AMSAC). Research guidelines for cookery sensory and instrumental tenderness measurement of fresh meat. Chicago, 1995. 48p.

ANJANEYULU, A.S.R.; SHARMA, A.S.R.; KONDAIAH, N. Evaluation of salt, polyphosphates and their blends at differents levels on physicochemical properties of Buffalo meat and patties. Meat Science, v.25, n.7, p.293-306, 1989.

BENDALL, J.R. El estimulo eletrico de las canales de los animales de abasto. In: LAWRIE, R.A. (Ed.). Avances de la ciencia de la carne. Zaragoza: Acribia, 1984. p.57-83.

BOLES, J.A.; SWAN, J.E. Effects of brine ingredients and temperature on cook yields and tenderness of pre-rigor processes roast beef. Meat Science, v.45, n.1, p.87-97, 1997. 
BOLES, J.A.; SHAND, P.J. Meat cut and injection level affects the tenderness and cook yield of processed roast beef. Meat Science, v.59, n.3, p.259-265, 2001.

BRASHEAR, G.; BREWER, M.S.; McKEITH, F.K. Effect of raw material pH, pump level and pump composition on quality characteristics of pork. Journal of Muscle Foods, v.13, n.8, p.189-204, 2002.

BREWER, M.S.; ZHU, L.; McKEITH, F.K. Marbling effects on consumers quality characteristics of pork. I Purchase intent, visual and sensory acceptability. In: ANNUAL RECIPROCAL MEAT CONFERENCE, 52., Stillwater, 1999. Proceedings. Stillwater: AMSAC, 1999. p.36.

CHOW, H.M.; OCKERMAN, H.W.; CAHILL, V.R.; PARRET, N.A. Evaluation of cured, canned pork shoulder tissue produced by electrical stimulation, hot processing and tumbling. Journal of Animal Science, v.51, n.3, p.288-291, 1986.

CONTRERAS, C.J.C. Efeitos do atordoamento elétrico, da estimulação e da desossa a quente na qualidade da carne do peito (músculo Pectoralis major) de frango. Campinas, 1995. 164p. Tese (Doutorado) - Universidade Estadual de Campinas.

CORTE, O.O. Utilização da estimulação elétrica seguida de desossa a quente segundo o processo desenvolvido no Centro de Tecnologia da Carne do Instituto de Tecnologia de Alimentos: proposta preparada para a Secretaria de Inspeção de Produtos Animais - SIPA. Campinas: ITAL, CTC, 1981. 29p. 
CROSS, H.R.; TENNENT, I. Accelerated processing system for USDA choice and good beef carcasses. Journal of Food Science, v.45, n.11, p.765769,1980 .

CUNNIF, P. Official methods of analysis of the Association of Official Analytical Chemist. 16.ed. Maryland: Aspen Publishers, 1998. 2v.

DELGADO, E.F. Fatores bioquímicos que afetam a maciez da carne. In: CONGRESSO BRASILEIRO DE CIÊNCIA E TECNOLOGIA DE CARNES, 1., São Pedro, 2001. Anais. Campinas: ITAL, CTC, 2001. p.149-155.

DRANSFIELD, E. Optimisation of tenderisation, ageing and tenderness. In: INTERNATIONAL CONGRESS OF MEAT SCIENCE AND TECHNOLOGY, 38., Clermont, 1994. Proceedings. Clermont: Ferrand, 1994. p.38-44.

DRANSFIELD, E.; BROWN, A.J.; RHODES, D.N. Predictors of beef tenderness: development and verification. Journal Food Technology, v.11, n.6, p.401408, 1976.

FAROUK, M.M.; HALL, W.K.; SWAN, J.E. Attributes of beef sausage batters, patties and restructured roast from two boning systems. Journal of Muscle Foods, v.11, n.5, p.197-212, 2000.

FNP CONSULTORIA \& COMÉRCIO. Anualpec 2003: anuário da pecuária brasileira. São Paulo, 2003. p.45-53.

FELÍCIO, P.E. de. A carne de Nelore para o consumidor. In: SEMINÁRIO MANAH, Brotas,1995. Anais. Campinas: Fazenda Mundo Novo, 1995. p.11. 
GAULT, N.F.S. The relationship between water holding capacity and cooked meat tenderness in some beef mescles as influenced by acidic conditions below the ultimate pH. Meat Science, v.15, n.1, p.15-17, 1985.

GEESINK, G.H.; MAREKO, M.H.D.; MORTON, J.D.; BICKERSTAFFE, R. Electrical stimulation: when more is less. Meat Science, v.57, n.3, p.145151, 2001.

GONZALEZ, C.B.; SALITTO V.A.; CARDUZA F.C.; PAZOS A.A.; LASTA J.A. Effect of calcium chloride marination on bovine Cutaneus trunci muscle. Meat Science, v.57, n.8, p.251-256, 2001.

GRIFFIN, C.L.; SHACKELFORD, S.D.; STIFFLER, D.M.; SMITH, G.C.; SAVELL, J.W. Storage and display characteristics of electrically stimulated, hot-boned and nonstimulated cold-boned beef. Meat Science, v.31, n.9, p.279-284,1992.

HALLIDAY, D.A. Phosphate in food processing. Process Biochemistry, v.13, n.1, p.7, 1978.

HALLORAN, G.R.; TROY, D.J.; BUCKLEY, D.J. The relationship between early post mortem, $\mathrm{pH}$ and the tenderisation of beef muscles. Meat Science, v.45, n.6, p.239-251,1997.

HAMM, R. Functional properties of the myofibrilar system and their measurement. In. BECHTEL, P.J. Muscle as food. New York: Academic Press, 1986. 135p.

HEDRICK, H.B. Principles of meat science. Kendall Hunt W.H.: Freeman Company, 1994. 354p. 
HILL, F. The solubility of intramuscular collagen in meat animals of various ages. Journal of Food Science, v.31, n.2, p.161-165, 1966.

HOES, T.R.; RAMSEY, C.B.; HINES, R.C.; TATUM, J.D. Yield and palatability of hot-process, phosphate-injected pork. Journal of Food Science, v.45, n.10, p.773-781,1980.

HUNT, M.C.; KENDALL, J.L.A.; DIKEMAN, M.E.; KASTNER, C.L.; KROPE, D.H. Ground beef from electrically stimulated and hot-boned carcasses. Meat Science, v.30, n.1, p.70-75, 1980.

HONIKEL, K.O. Effect of handling ante, intra and early post mortem on characteristics of beef with regard to the velocity of chilling. Journal Animal Science, v.40, n.1, p.35-40, 1987.

JUDGE, M.D.; ABERLE, E.D. Effects of prerigor processing on the oxidative rancidity of ground light and dark porcine muscles flavor stability. Journal of Food Science, v.45, n.15, p.1736-1740,1980.

KASTNER, C.L.; FELÍCIO, P.E. de. Tratamentos que influem na maciez da carne bovina no período pós-abate. Campinas: ITAL,1980. 64p. (Boletim Técnico do CTC, 5)

KEETON, J.T. Effects of fat and $\mathrm{NaCl}$ and phosphate levels on the chemical and sensory properties of pork patties. Journal of Food Science, v.48, n.10, p.878-881, 1983. 
KOOHMARAIE, M. The role of endogenous proteases in meat tenderness. In: ANNUAL RECIPROCAL MEAT CONFERENCE NATIONAL LIVESTOCK AND MEAT BOARD, 41., Laramie,1988. Proceedings. Laramie: National Livestock, 1988. p.95-100.

KOOHMARAIE, M.; SHACKELFORD, S.D. Effects of calcium chloride infusion on the tenderness of lamb fed a $\beta$ - adrenergic agonist. Journal of Animal Science, v.69, n.6, p.2463-2471, 1991.

KOOHMARAIE, M.; WHIPPLE, G.; CROUSE, J.D. Acceleration of postmortem tenderization in lamb and brahman-cross beef carcasses through infusion of calcium chloride. Journal of Animal Science, v.68, n.5, p.1278-1283, 1990.

LANDSELL, J.; MILLER, M.F.; WHEELER, T.L. Postmortem injection of calcium chloride effects on beef quality traits. Journal Animal Science, v.73, n.6, p.1735 -1740, 1995.

LAWRIE, R.D. Meat science. New York: Academic Press,1985. p.74-91: The conversion of muscle to meat.

LAWRENCE, T.E.; DIKEMAN, M.W.; STEPHENS, J.W.; OBUZ, E.; DAVIS, J.R. Situ investigation of the calcium-induced proteolytic and salting in mechanism causing tenderization in calcium-enhanced muscle. Meat Science, v.66, n.1, p.69-75, 2003.

LEE, B.J.; HENDRICKS, D.G.; CORNFORTH, D.P. Effects of sodium phytate, sodium pyrophosphate and sodium tripolyphosphate on physico-chemical characteristics of restructured beef. Meat Science, v.50, n.3, p.273-283, 1998. 
LEMOS, A.L.S.C.; NUNES, D.R.M.; VIANA, A.G. Optimization of still marination process of chicken parts. Meat Science, v.52, n.2, p.227-234, 1999.

MACDOUGALL, D.B. Color of meat. In: PEARSON, A.M., DUTSON, T.R. Advances in meat research: quality attributes and their measurement in meat, poultry and fish products. Maryland: Aspen Publishers, 1994. p.45-64.

McGEE, M.R.; HENRY, K.L.; BROOKS, J.C.; RAY, F.K.; MORGAN, J.B. Injection of sodium chloride, sodium tripoliphospahte and sodium lactate improves Warner Bratzler shear and sensory characteristics of pre cooked inside round roasts. Meat Science, v.64, n.4, p.273-277, 2003.

MILLER, R.K. United States iniciatives to reduce variability in beef and pork eating quality. In: INTERNATIONAL CONGRESS OF MEAT SCIENCE AND TECHNOLOGY, 43., Auckland, 1997. Proceedings. s.l.: s.ed., 1997. p4552.

MOLINS, R.A.; KRAFT, A.A.; MARCY, J.A. Extension of the shelf-life of fresh ground pork with polyphsphates. Journal of Food Science, v.52, n.2 p.513514, 1987.

MORGAN, J.B.; MILLER, R.K.; MENDEZ, F.M.; HALE, D.S.; SAVELL, J.W. Using calcium chloride injection to improve tenderness of beef from mature cows. Journal of Animal Science, v.69, n.14, p.4469-4476, 1991.

ORESKOVICH, D.C.; BECHTEL, P.J.; McKEITH, F.K. Marinade pH affects textural properties of beef. Journal of Food Science, v.57, n.2, p.305-311, 1992. 
PATERSON, B.C.; PARRISH, F.C. Jr. A sensory panel and chemical analysis of certain beef chuck muscles. Journal of Food Science, v.51, n.7, p.876896, 1986.

PAZOS, A.A.; SALITTO, V.A.; LASTA, J.A.; GONZALEZ, C.B. Tenderness improvement of bovine Biceps femoris muscle by calcium chloride injection. Journal of Muscle Foods, v.13, n.3, p.171-187, 2002.

PISULA, A.; TYBURCY, A. Hot processing meat. Meat Science, v.42, n.2, p.125-134,1996.

ROCHA, A.E. El marinado de la carne de ave. Revista CarneTec, v.3, n.1, p.28-32, Set./Out. 2000.

SCHMIDT, G.R.; KEMAN, S. Hot boning and vacuum packaging of eight major bovine muscles. Journal of Food Science, v.39, n.2, p.140-142, 1974.

SCHMIDT, G.R.; GILBERT, K.V. The effect of muscle excision before the onset of rigor mortis on the palatability of beef. Journal of Food Technology, v.5, n.4, p.331, 1970.

SHEARD, P.R.; JOLIEY, P.D.; KATIB, A.M.A.; ROBINSON, J.M.; MORLEY, M.J. Influence of sodium chloride and sodium tripolyphosphate on the quality of UK- style grill steaks relationship to freezing point depression. International Journal of Food Science and Technology, v.25, n.7, p.643656, 1990.

SHEARD, P.R.; NUTE, G.R.; RICHARDSON, R.I. Injection of water and polyphosphate into pork to improve juiciness and tenderness after cooking Meat Science, v.51, n.4, p.371-376, 1999. 
SMITH, L.A.; SIMMONS, S.L.; McKEITH, F.K.; BECHTEL, P.J.; BRADY, P.L. Effect of sodium tripolyphosphate on physical and sensory properties of beef and pork roasts. Journal of Food Science, v.49, n.13, p.1636, 1984.

STITES, C.R.; McKEITH, F.K.; BECHTEL, P.J.; CARR, T.R. Palatability and storage characteristics of precooked beef roasts. Journal of Food Science, v.54, n.1, p.3-6, 1989.

SOFOS, J.N. Use of phosphates in low-sodium meat products. Food Technology, v.40, n.1, p.52-56, Sept. 1986.

STEINHAUER, J.E. Food phosphates for use in the meat, poultry and seafood industry. Dairy and Food Sanitation, v.3, n.3, p.244-249, 1983.

SWIFT, C.E.; BREMAN, M.D. Factors affecting the water retention of beef. I. Variations in composition and properties among eight muscles. Food Technology, v.13, n.4, p.365-370, 1959.

SZCZESNIAK, A.S. Developments of standard rating scales for mechanical parameters of texture and correlation between the objective and the sensory methods of texture evaluation. Journal of Food Science, v.28, n.4, p.397402, 1963.

SZCZESNIAK, A.S. Texture is a sensory property. Food Quality and Preference, v.13, n.2, p.215-225, 2002.

TAYLOR, A.A.; SHAW, B.G.; MACDOUGALL, D.B. Hot deboning beef with and without electrical stimulation. Meat Science, v.5, n.2, p.109-123, 1981. 
TAYLOR, R.G. Meat tenderness: theory and practice. Brazilian Journal of Food Technology, v.6, n.1, p.61-65, 2003.

URBAIN, W.M.; GIDDINGS, G.G.; BELO, P.S.; BALLANTYNE, W.W. Radiation pasteurization of fresh meats and poultry. s.l.: s.ed., 1968. 2p.

XARGAYÓ, M. Marination of fresh meats by means of spray effect. Fleischwirtschaft International, v.2, n.1, p.70-74, 2001.

YOUNG, L.L.; PAPA, C.M.; LYON, C.E.; WILSON, R.L. Moisture retention and textural properties of ground chicken meat affect by sodium tripolyphosphate, ionic strenght, and pH. Journal of Food Science, v.57, n.9, p.1291-1293, 1992.

YU, L.P.; LEE, Y.B. Effects of postmortem $\mathrm{pH}$ and temperature on bovine muscle structure and meat tenderness. Journal of Food Science, v.51, n.8, p.774-779, 1986. 